Ann. Génét. Sél. anim., I974, 6 (3), 305-329.

\title{
COMPARAISON DU POLYMORPHISME GÉNÉTIQUE DES LACTOPROTÉINES DU ZÉBU ET DES BOVINS
}

\author{
F. GROSCLAUDE, Marie-Françoise MAHÉ et J.-C. MERCIER \\ Laboratoire de Génétique biochimique \\ et Laboratoire de Recherches sur les Protéines, \\ Centre national de Recherches zootechniques, I. N. R. A., \\ 78350 Jouy en Josas
}

\section{RÉSUMÉ}

778 lactosérums et 586 solutions de caséines préparés à partir de laits individuels de zébus malgaches ont été examinés par électrophorèse en gel d'amidon ou d'acrylamide dans le but d'analyser le polymorphisme génétique des protéines du lait de zébu (Bos indicus), et de le comparer à celui du lait bovin (Bos taurus).

Les loci de structure des cinq principales lactoprotéines ( $\alpha$-lactalbumine, $\beta$-lactoglobuline, caséines $\alpha_{s_{1}}$, $\beta$ et $x$ ) sont tous bialléliques et déterminent les variants classiques suivants : La $\mathrm{A}$ et $\mathrm{B} ; \mathrm{Lg} \mathrm{A}$ et $\mathrm{B} ; \alpha_{s_{1}}-\mathrm{B}$ et $\mathrm{C} ; \beta \mathrm{A}^{1}$ et $\mathrm{A}^{2} ; \varkappa \mathrm{A}$ and $\mathrm{B}$. Les variants $\beta \mathrm{B}$ et $\beta \mathrm{D}$ n'ont pas été trouvés au cours de cette étude. Les fréquences alléliques observées dans l'échantillon, ainsi que les fréquences des combinaisons alléliques contrôlées par l'unité génétique formée des trois loci, $\alpha_{s_{1}}-\mathrm{Cn}, \beta-\mathrm{Cn}$ et $\varkappa_{-} \mathrm{Cn}$, sont indiquées dans le tableau $\mathbf{I}$. La comparaison des fréquences alléliques observées dans les cinq sous-échantillons géographiques les plus importants indique que la population de zébus considérée présente une certaine homogénéité génétique.

Les substitutions d'acides aminés responsables des différences de mobilité électrophorétique entre les variants $\alpha_{s_{1}} \mathrm{~B}$ et $\mathrm{C}, \beta \mathrm{A}^{1}$ et $\mathrm{A}^{2}$ et $x \mathrm{~A}$ et $\mathrm{B}$, ont été caractérisées en suivant, en général, les méthodes précédemment appliquées par notre équipe à l'étude des variants des caséines bovines. Elles sont toutes identiques aux substitutions trouvées chez les bovins, y compris lorsque les variants $\alpha_{s_{1}}$-C et $\beta \mathrm{A}^{1}$ sont commandés par la combinaison allélique $\alpha_{s_{1}}-\mathrm{Cn}^{\mathrm{C}}-\beta-\mathrm{Cn} \mathrm{A}^{1}$ [substitutions I92 Glu $\left(\alpha_{s 1}-\mathrm{B}\right) \rightarrow \operatorname{Gly}\left(\alpha_{s_{1}}-\mathrm{C}\right), 67$ Pro $\left(\beta \mathrm{A}^{2}\right) \rightarrow$ His $\left(\beta \mathrm{A}^{1}\right)$ et $\mathrm{I}_{4} 8 \mathrm{Asp}(\varkappa \mathrm{A}) \rightarrow \mathrm{Ala}(\varkappa \mathrm{B})$ ]. Par ailleurs, l'étude d'un échantillon de caséine $\beta B$, préparé à partir du lait d'un zébu $C h o a$ (République Tchadienne), indique que ce variant diffère de $\beta \mathrm{A}^{\mathbf{1}}$, comme chez les bovins, par la substitution 122 Ser $\left(\beta A^{1}\right) \rightarrow \operatorname{Arg}(\beta B)$, ce qui rend discutable l'utilisation d'une notation particulière $(\beta \mathrm{Bz})$ pour désigner le variant $\beta \mathrm{B}$ du zébu. Selon toute vraisemblance, et pour chacun des trois loci, le polymorphisme commun à Bos taurus et à Bos indicus dérive de mutations uniques, antérieures à la divergence phylogénétique de ces deux rameaux du genre Bos, qui s'est produite, selon EPSTEIN (I97I), en Asie du sud-ouest, vers les quatrième et troisième millénaires avant notre ère. Le fait que l'allèle prédominant du locus $\alpha_{s_{1}}$-Cn ne soit pas le même chez Bos taurus $\left(\alpha_{s_{1}}-\mathrm{B}\right)$ que chez Bos indicus $\left(\alpha_{s_{1}}-\mathrm{C}\right)$ peut être dû au jeu de la dérive génétique pendant la phase de sélection en effectif limité qui a sans doute accompagné la domestication.

Outre les deux substitutions déjà trouvées chez les bovins - I48 Asp $(\varkappa \mathrm{A}) \rightarrow \mathrm{Ala}(\chi \mathrm{B})$ responsable de la différence de charge nette, et I36 $\mathrm{Thr}(\varkappa \mathrm{A}) \rightarrow$ lle $(\varkappa \mathrm{B})$, sans effet sur la charge les " caséino-macropeptides" les variants $x \mathrm{~A}$ et $\varkappa \mathrm{B}$ diffèrent, chez le Zébu malgache, par une troisième substitution, I35 lle $(x \mathrm{~A}) \rightarrow$ Thr $(x \mathrm{~B})$, sans effet sur la charge. Compte tenu du petit nombre d'échantillons de caséine étudiés dans les deux cas, on ne peut tirer, de cette observation, aucune conclusion générale. 
Un échantillon de caséine $\beta D$ a été préparé à partir de prélèvements de laits individuels provenant de deux sujets Yak $\times$ Zébu népalais; $\beta D$ diffère de $\beta A^{2}$ par la substitution r 8 SerP $\left(\beta A^{2}\right) \rightarrow$ Lys $(\beta D)$, qui est, selon toute vraisemblance, la seule substitution impliquée dans la différence de charge nette entre ces deux variants.

Contrairement à ce qui s'observait dans les données, peu nombreuses il est vrai, de Blumberg et Tombs (1958), la répartition des génotypes aux loci $\alpha$-La et $\beta$-Lg dans notre échantillon de population de zébus malgaches est tout à fait conforme à celle qui est attendue dans l'hypothèse d'indépendance génétique entre ces deux loci. En ce qui concerne les loci $\alpha_{s_{1}}-C_{n}$ et $\beta-C n$, on ne retrouve pas, dans la population de zébus considérée, où la combinaison allélique $\alpha_{s_{1}}-\mathrm{Cn}_{1} \mathrm{C}-\beta-\mathrm{Cn}^{\mathrm{A}^{1}}$ coexiste avec les combinaisons $\alpha_{s_{1}}-\mathrm{Cn}^{\mathrm{B}}-\beta-\mathrm{Cn}_{\mathrm{A}^{2}}, \alpha_{\delta_{1}}-\mathrm{Cn}^{\mathrm{B}}-\beta-\mathrm{Cn}^{\mathrm{A}^{1}}$ et $\alpha_{\delta_{1}}-\mathrm{Cn} \mathrm{n}_{-}-\beta-\mathrm{Cn}^{\mathrm{A}}$, un déséquilibre de linkage aussi accusé que celui qui s'observe dans de nombreuses races bovines occidentales, françaises notamment. Cette situation particulière peut s'expliquer par le fait que l'effectif génétique de la population de zébus malgache est sans doute beaucoup plus élevé que celui de la plupart des races bovines occidentales.

\section{INTRODUC'TION}

De rapides progrès ont été réalisés, au cours de ces dernières années, dans le domaine de la biochimie des principales lactoprotéines bovines et de leurs variants génétiques : la structure primaire de l' $\alpha$-lactalbumine (BREW et al., I970), celle de de la $\beta$-lactoglobuline (BRAUNITZER et al., I972), et celle des caséines $\alpha_{s_{1}}$ (MERCIER et al., I97I), $\beta$ (RIBADEAU-DumAs et al., I972), et $x$ (MERCIER et al., I973) ont, en effet, été complètement élucidées ; d'autre part, toutes les altérations différenciant les variants génétiques de la $\beta$-lactoglobuline (BRAUNITZER et al., I972; BRIGNON et al., I973) et des caséines $\alpha_{s_{1}}$, $\beta$ et $\varkappa$ (GROsclaUde et al., I972, $a, b ; 1974 b$ ) ont été identifiées et localisées, à l'exception de la substitution His/Gln caractérisant le variant $\beta$-Lg C (BELL et al., I968) qui n'a pas été définitivement localisée dans la chaîne polypeptidique de la $\beta$-lactoglobuline ( $\left.{ }^{(}\right)$.

Le déterminisme génétique des caséines $\alpha_{s_{1}}, \beta$ et $x$ bovines présente des caractères originaux : ces trois protéines sont en effet sous le contrôle de trois loci de structure très étroitement liés; ceci se traduit, au niveau des populations, et surtout entre les allèles des loci $\alpha_{s_{1}}$-Cn et $\beta$-Cn, par un déséquilibre de linkage très accusé, caractérisé par l'absence ou l'extrême rareté de certaines combinaisons alléliques, ou " complexes géniques " (voir l'analyse récente de GrosclaudE et al., $\mathrm{I} 972 \mathrm{c}$ ).

Les diagrammes d'électrophorèse de lactosérums et de caséines de zébu (Bos indicus) présentent, avec ceux des bovins (Bos taurus), une remarquable similitude. Les variants bovins les plus fréquents se retrouvent en effet chez le Zébu, et les différences relevées jusqu'à présent entre les deux sous-genres ne portent que sur leurs variants les moins répandus. Sur la base des inventaires effectués jusqu'à présent - beaucoup plus nombreux chez les bovins - les variants électrophorétiques des 5 lactoprotéines principales peuvent se classer comme suit :

- variants présents à la fois chez les bovins et les zébus :

$\alpha_{s_{1}}-\mathrm{Cn} B$ et $\mathrm{C} ; \beta-\mathrm{Cn} \mathrm{A}^{1}, \mathrm{~A}^{2}$ et $\mathrm{B} ; \boldsymbol{x}$-Cn A et B; $\beta$-Lg A et B ; $\alpha$-La A et B. $A$ noter que le variant $\alpha$-La $A$, qui a pu être considéré comme spécifique du zébu, existe en fait dans certaines races bovines (GROSCLAUDE, I968);

(1) Les données de BELL et al. ( 1968 ) semblent toutefois indiquer que cette substitution se situe en position 59 dans la séquence établie par BRAunitzer et al. (1972). 
- variants qui ne semblent présents que chez les bovins :

$\alpha_{s_{1}}$ Cn $A$ et $D ; \beta-C n A^{3}$, C et $E ; \beta-L g C$ et $D$;

- variant qui ne semble présent que chez les zébus : $\beta$-Cn $D$.

A l'exception du travail de BELL et al. (I970) sur le variant $\alpha$-La A, aucune étude biochimique complète n'a été effectuée sur les variants des lactoprotéines de zébu. Cependant, le fait que les principaux variants des lactoprotéines de bovins et de zébus se correspondent exactement en électrophorèse ne signifie pas nécessairement que ces variants diffèrent, dans les deux sous-genres, par les mêmes substitutions d'acides aminés. Les résultats obtenus jusqu'ici sur les caséines $\alpha_{s_{1}}$ et $\beta$ (AschAFFENBURG et al., I968; THOMPSON et al., I969) ont donné, sur ce point, des indications divergentes : en effet, les fingerprints trypsiques et chymotrypsiques du variant $\alpha_{s_{1}} \mathrm{C}$, comme du variant $\beta-\mathrm{A}^{2}$, paraissent identiques chez Bos taurus et chez Bos indicus; par contre les fingerprints et la composition globale en acides aminés $\mathrm{du}$ variant $\beta-\mathrm{B}$ présentent quelques différences entre les deux sous-genres, ce qui a conduit à introduire une notation différente pour le variant $\beta-B$ de zébu $(\beta \mathrm{Bz})$.

Sur le plan génétique, l'existence chez le Zébu, d'un déséquilibre de linkage entre les allèles des loci $\alpha_{s_{1}}$ - $\mathrm{Cn}$ et $\beta$-Cn (AschafFENBuRG et al., I968) révèle, comme on pouvait s'y attendre, la même organisation génétique que chez les bovins. Par contre, la prédominance de l'allèle $\alpha_{s_{1}}-\mathrm{Cn}^{\mathrm{c}}$, qui est de règle dans les populations de zébus, contraste avec celle de 1'allèle $\alpha_{s_{1}}-\mathrm{Cn}^{\mathrm{B}}$ dans les populations bovines (AschafFenbuRG, I968); cette différence appelle une explication et incite par ailleurs à rechercher si, dans ces conditions, les combinaisons alléliques de l'unité génétique $\alpha_{s_{1}} \mathrm{Cn}-\beta-\mathrm{Cn}-x-\mathrm{Cn}$ sont, chez Bos indicus, les mêmes que chez Bos taurus.

Il nous a donc semblé intéressant, pour prolonger notre analyse génétique et biochimique du polymorphisme des caséines bovines (GROSCLAUDE et al., I966; I972 $a, b, c)$, d'entreprendre un travail similaire chez le Zébu, en nous attachant d'une part à inventorier les variants électrophorétiques et les combinaisons alléliques propres à Bos indicus à partir d'un échantillon de population assez important, et d'autre part à identifier les altérations différenciant les variants ainsi détectés pour les comparer à celles qui différencient les variants de Bos taurus.

Il paraissait également indiqué de profiter de l'existence, qui est de règle chez le Zébu (Bhattacharya et al., I963; AschafFenburg, I968) d'un polymorphisme de 1' $\alpha$-lactalbumine pour tenter de préciser les relations existant entre les loci $\alpha$-La et $\beta$-Lg; Blumberg et Tombs (I958) ont en effet publié des données suggérant que ces loci pouvaient être génétiquement liés, ce que personne ne semble avoir tenté de vérifier par la suite.

Le travail qui fait l'objet de la présente publication a été entrepris, à l'aide de lait de zébus provenant de la République Malgache, pour tenter de répondre à l'ensemble de ces questions. L'absence des variants $\beta B z$ et $\beta D$ dans cet échantillon de population nous a par ailleurs conduits à faire appel, pour l'étude biochimique de ces variants, à d'autres sources de caséines de zébus (République Tchadienne, Népal). 


\section{MATÉRIEL ET MÉTHODES}

\section{Origine et conditionnement des échantillons}

788 échantillons individuels de lait de zébu ont été prélevés par l'un de nous (J.-C. M.) du I 5 mars au 8 avril 1968, dans les troupeaux expérimentaux ou dans les élevages localisés comme suit (entre parenthèses : nombre d'échantillons) : troupeaux expérimentaux des Centres de Recherches de Kianjasoa (17), Sainte-Marie (24) et Miadana (58); élevages des régions de Kianjasoa (26), Miadana (I 5), Majunga (I 28), Tuléar (87), Betioky (97), Ejeda (36), Ampanihy (82), Beloha (4I), Ambovombe (28), Isoanala (94) et Betroka (55). (voir fig. I). Ces échantillons ont été autant que possible maintenus au frais (vers $+4^{\circ} \mathrm{C}$ ), après addition d'une solution aqueuse de bichromate de potassium ( $\mathrm{I} \mathrm{g} / \mathrm{l}$ ) à raison de 2 gouttes pour un tube de $\mathrm{I} 5 \mathrm{ml}$.

Après détermination, à Jouy en Josas, de leurs variants génétiques, 3 échantillons individuels provenant du Centre de recherches de Kianjasoa, et 2 d'un élevage de la même région, ont été prélevés en plus grande quantité (environ I litre) ; 6 autres échantillons individuels d'un litre environ ont été prélevés au hasard dans la région de Majunga. Pour ces prélèvements, le bichromate de potassium a été remplacé par du toluène $(5 \mathrm{ml}$ par flacon d'un litre). vement.

Tous les échantillons ont été expédiés en France par avion au fur et à mesure de leur prélè-

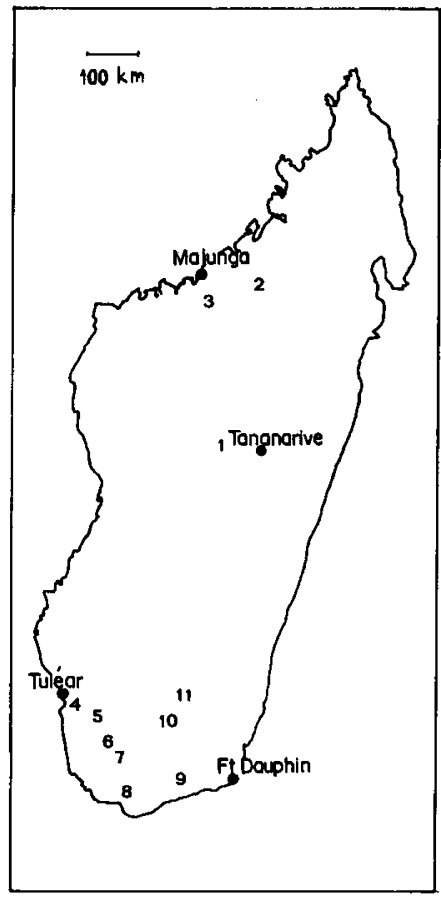

FIG. I. - Régions de provenance des prélèvements de laits individuels de zébus malgaches:

I : Kianjasoa ; 2 : Sainte-Marie, Miadana ; 3 : Majunga ; 4 : Tuléar ; 5 : Betioky ;

6: Ejeda ; 7 : Ampanihy ; $8:$ Beloha ; $9:$ Ambovombe; ro : Isoanala; 1 I : Betroka.

\section{Origine des produits}

A l'exception de la thermolysine (Merck $6000 \mathrm{PU} / \mathrm{mg}$ ) et de l'amino-peptidase M (Röhm $2500 \mathrm{mU} / \mathrm{mg}$ ) les enzymes utilisées proviennent de la firme Worthington Biochemical Corporation : trypsine $(2 \times$ cristallisée TRL $7 \mathrm{AA})$; leucine aminopeptidase (LAP DFP $5,9 \mathrm{mg} / \mathrm{ml})$; 
carboxypeptidase A (COA DFP $50 \mathrm{mg} / \mathrm{ml})$; carboxypeptidase B (COB DFP 2,9 $\mathrm{mg} / \mathrm{ml}$ ); phosphatase alcaline (BAPC OCB Io $\mathrm{mg} / \mathrm{ml}$ ).

L'origine des autres produits est la suivante : anhydride maléique Prolabo; isothiocyanate de phényle, Fluka redistillé ; acide trifluoracétique, Eastman; bromure de cyanogène, Schuchardt; hydrazine hydratée, Prolabo, retraitée au laboratoire (indice de réfraction de l'hydrazine anhydre obtenue : $\alpha_{\mathrm{D}}^{22}=1,467$ ); Dowex AG 50 WX 2, 200-400 mesh, Biorad; Sephadex, Pharmacia.

\section{Préparation des caséines entières et des lactosérums}

Les caséines et les lactosérums ont été préparés, à partir des I I prélèvements de lait d'un litre, selon la technique décrite par Mercier et al. (1968) ; par contre, les 788 échantillons de petit volume ont été traités par la technique simplifiée d'Aschaffenburg et DrewRY (I959). Les lactosérums ont été conservés à $+4^{\circ} \mathrm{C}$, et les caséines, lyophilisées.

\section{Préparation des caséines $\alpha_{s_{1}}, \beta$ et $x$}

Les caséines $\alpha_{\delta_{1}}, \beta$ et $\chi$ ont été préparées par chromatographie sur colonne de DEAE-cellulose selon Mercier et al. (1968). Pour la caséine $x$, nous avons retenu la fraction principale, dépourvue de glucides (fraction $x \mathrm{~A}_{1}$ pour le variant $x \mathrm{~A}, x \mathrm{~B}_{1}$ pour le variant $x \mathrm{~B}$ ).

\section{Techniques d'électrophorèse}

Chaque échantillon de caséine a été examiné par trois techniques d'électrophorèse différentes : a) gel d'acrylamide à $\mathrm{pH} 9,2$ selon Peterson $(\mathbf{r g 6 3}) ; b$ ) gel d'amidon à $\mathrm{pH} 8,6$ selon Wake et Baldwin (I96I) ; c) gel d'amidon à pH 3,0, avec les mêmes tampons que ceux de Peterson et KOPFLER (I966) mais dilués au demi. Les gels sont toujours additionnés de $\beta$-mercaptoéthanol (concentration finale d'environ $0,03 \mathrm{M}$ ).

Les échantillons de lactosérums ont été examinés par les mêmes techniques d'électrophorèse en gel d'amidon $(\mathrm{pH} 8,6$ et 3,0$)$ que les caséines.

\section{Techniques biochimiques}

A l'exception de la technique de dosage de la phosphosérine appliquée dans l'étude du seul variant $\beta D$, toutes les techniques utilisées dans ce travail ont été décrites dans nos publications antérieures : maléylation, électrophorèses et chromatographies sur papier, chromatographies sur colonnes de DEAE-cellulose, Dowex et Sephadex, dosage des acides aminés, dosage du phosphore, hydrolyse par la trypsine (GROSCLAUde et al., I97o a) ; dégradation soustractive d'Edman, hydrolyse par la chymotrypsine, la pepsine, les carboxypeptidases A et B, la leucine aminopeptidase, (MERCIER et al., I970 $a$, complété, pour la carboxypeptidase A, par Grosclaude et al., I970 $b$ ) ; hydrolyse par le bromure de cyanogène (MERCIER et al. I970 $b$ ) par la thermolysine (Ribadeau-Dumas et al., I97 I a), par la phosphatase alcaline (Ribadeau-Dumas et al., I97 I $b$ ) ; hydrolyse par la leucine aminopeptidase M et hydrazinolyse (RIBAdEaU-Dumas et al., 1972). A noter que, pour les hydrolyses enzymatiques à $\mathrm{pH}$ alcalin, le tampon Tris- $\mathrm{HCl}$ a été remplacé, en général, par un tampon volatil, l'acétate de $\mathrm{N}$-éthylmorpholine, o, $2 \mathrm{M}, \mathrm{pH} 8,6$ (HUANG et TANG, 1970).

\section{Technique de dosage de la phosphosérine appliquée dans l'étude du variant $\beta D$}

Le peptide, préalablement desséché, est soumis, pendant 5 heures, à une hydrolyse acide ménagée dans $\mathrm{HCl}$ concentré à $80^{\circ} \mathrm{C}$, en tube scellé sous vide ; les acides aminés libérés, y compris 1a phosphosérine, sont dosés à l'analyseur d'acides aminés : le rapport de la quantité de phosphosérine à la quantité unitaire d'un autre acide aminé peut donner une excellente estimation de la teneur du peptide en phosphosérine : c'est ainsi que pour le peptide $\beta A^{2} \mathrm{TI}_{\mathrm{I}}$, qui contient 4 phosphosérines et une glycine, le rapport PSer/Gly est, en moyenne, pour 5 mesures indépendantes, de $3,88 \pm 0,20$.

\section{Techniques biophysiques}

La spectrométrie de masse a été effectuée, après $\mathrm{N}$-acétylation et perméthylation selon Vilkas et al. (1968) et Thomas (1969). 


\section{Nomenclature des peptides}

La nomenclature des peptides résultant de l'hydrolyse d'un peptide plus long fait intervenir dans l'ordre, trois éléments : $a$ ) la dénomination du peptide de départ, $b$ ) les initiales du nom de l'enzyme ou du réactif ayant servi à l'hydrolyse $(\mathrm{Th}=$ thermolysine ; $\mathrm{CN}=$ bromure de cyanogène, etc.), c) un numéro d'ordre, attribué en fonction du résultat de l'opération de fractionnement effectuée. Le numérotage des peptides se fait dans l'ordre d'élution pour une chromatographie sur colonne, de l'anode vers la cathode pour une électrophorèse préparative sur papier, et dans le sens des mobilités croissantes pour une chromatographie préparative sur papier. Par ailleurs l'appellation du peptide comporte, si besoin est, le nom du variant génétique dont il provient.

\section{RÉSULTATS}

I. - Analyse génétique du polymorphisme électrophorétique de l' $\alpha$-lactalbumine, de la $\beta$-lactoglobuline et des caséines $\alpha_{s_{1}}$, $\beta$ et $x$

I. I. Inventaire et fréquence des variants génétiques.

Par suite du mauvais état de conservation du quart environ des prélèvements de lait individuels, l'analyse du polymorphisme des caséines ne porte au total que sur 586 des 788 prélèvements effectués; par contre 1'analyse du polymorphisme de $1^{\prime} \alpha$-lactalbumine et de la $\beta$-lactoglobuline a pu se faire sur 778 prélèvements.

\section{TABLEAU I}

Fréquences alléliques aux loci $\alpha_{s_{1}}-C n, \beta-C n$ et $x-C n$, et fréquences des combinaisons alléliques de l'unité génétique formée par ces trois loci, calculées sur un échantillon de 586 vaches zébu: fréquences alléliques aux loci $\alpha-L a$ et $\beta-L g$, calculées sur un échantillon de 778 vaches zébu.

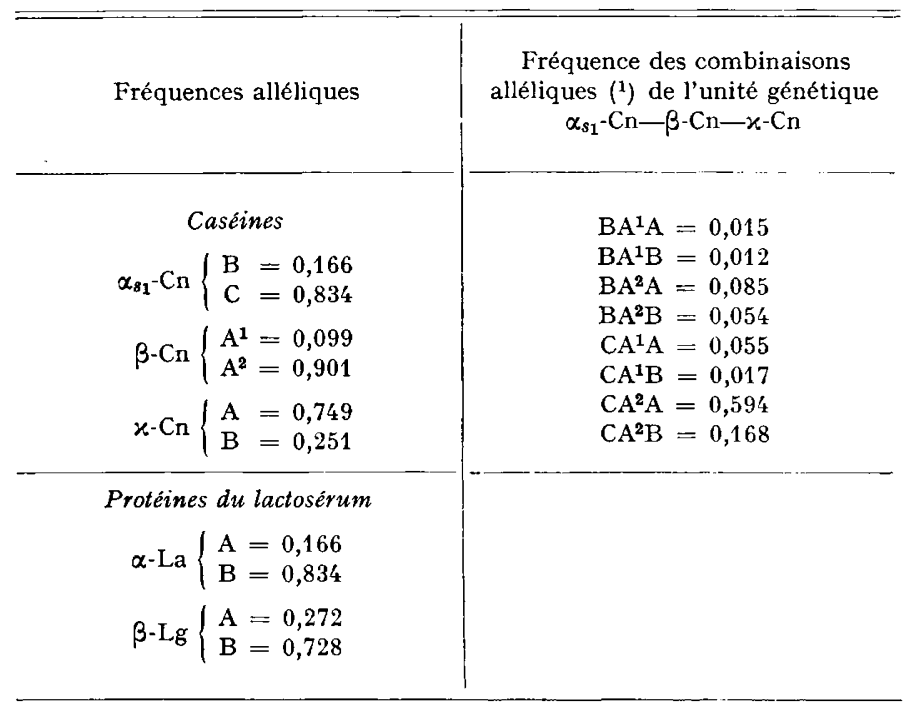

(1) Pour $\mathrm{BA}^{\mathbf{1}} \mathrm{A}$, lire : $\alpha_{s_{1}}-\mathrm{Cn}^{\mathrm{B}}-\beta-\mathrm{Cn}^{\mathbf{1}}-\chi-\mathrm{Cn} \mathrm{A}$, etc. 
On constate (tabl. I) que les loci de structure des 5 lactoprotéines principales sont tous bialléliques dans l'échantillon de population étudié ; ils déterminent les variants classiques suivants : $\alpha_{s_{1}}-\mathrm{Cn} B$ et $C, \beta-\operatorname{Cn} A^{1}$ et $A^{2}, x-C n A$ et $B, \alpha-L_{1}$ a et $B$, $\beta-\mathrm{Lg} A$ et $B$. Notre échantillon n'étant pas représentatif d'une population bien définie, les fréquences observées, qui sont données dans le tableau $I$, n'ont pas été assorties d'intervalles de confiance. On notera toutefois qu'un test d'homogénéité, appliqué aux fréquences calculées dans les 5 sous-échantillons provenant des régions ayant fourni les plus grands nombres de prélèvements, indique que la population de zébus sondée présente une réelle homogénéité (tabl. 2). L'échantillon total peut donc être considéré comme relativement représentatif de l'ensemble des régions d'élevage visitées.

\section{TABLEAU 2}

Fréquences alléliques aux loci $\alpha-L a, \beta-L g, \alpha_{s 1}-C n, \beta-C n$ et $x-C n$ dans les sous-échantillons provenant de 5 régions ayant fourni le plus grand nombre de prélèvements de laits individuels, et tests d'homogénéité des ces fréquences. Chaque locus étant biallélique, un seul allèle suffit à le caractériser.

En italiques ; effectif de l'échantillon, qui n'est pas nécessairement le même, dans une même région, pour les différents loci (dégradation inégale des diverses espèces protéiques dans les prélèvements mal conservés).

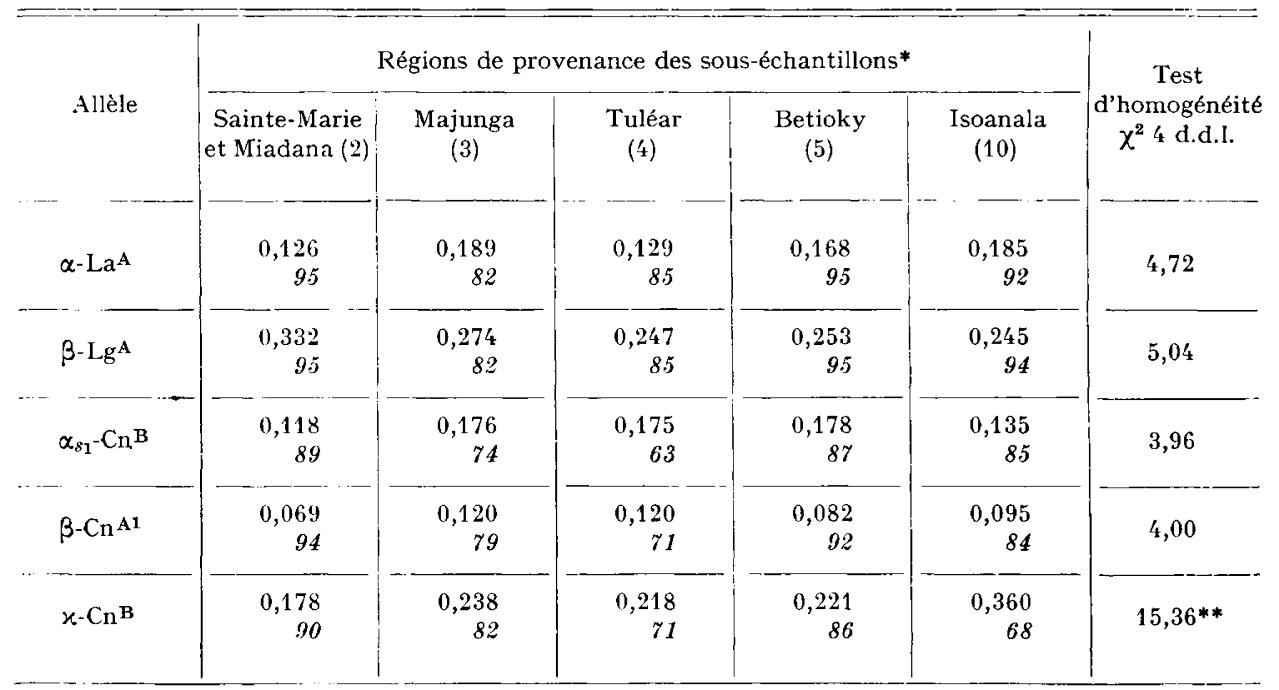

* Significatif au seuil de 1 p. 100 , mais la fréquence de $x-\mathrm{Cn}^{\mathrm{B}}$ dans la région (10) peut être surestimée

** Entre parenthèses le numéro indiquant ces régions sur la figure 1.

On retrouve chez le Zébu malgache deux caractéristiques de toutes les races ou populations de zébus étudiées jusqu'à présent : l'existence d'un polymorphisme au locus $\alpha$-La, et la nette prédominance, au locus $\alpha_{s_{1}}$ - $\mathrm{Cn}$, de l'allèle $\alpha_{s_{1}}$ - Cnc (AschaFFENBURG, I968; AsChAFFENBURG et al., I968) qui contraste avec la prédominance de l'allèle $\alpha_{s_{1}}-\mathrm{Cn}^{\mathrm{B}}$ dans toutes les races bovines. Par contre, on notera, l'absence inhabituelle, au locus $\beta-\mathrm{Cn}$, des variants $\beta \mathrm{Bz}$ et $\beta \mathrm{D}$. 
1. 2. Relation génétique entre les loci $\alpha-L a$ et $\beta-L g$.

Le tableau 3 donne la répartition des 778 vaches zébus de notre échantillon en fonction de leur génotype aux loci $\alpha-L_{1}$ et $\beta-L_{\text {g }}$. On note un excès significatif d'hétérozygotes au locus $\alpha$-La (dernière colonne; $\chi^{2}=4,2$; I ddl; $P<0,05$ ), mais, contrairement à ce qui semblait apparaître dans les données, très peu nombreuses il est vrai (46 laits individuels), de BLumberg et Tombs (I958), la répartition observée, calculée à partir des répartitions marginales, concorde remarquablement avec celle qui est attendue dans l'hypothèse d'indépendance génétique des deux loci.

TABLEAU 3

Répartition de 778 vaches zébu en fonction de leur génotype aux loci $\alpha$-La et $\beta-L g$

Entre parenthèses : nombres attendus dans l'hypothèse d'équilibre génétique ; en italiques : nombres attendus dans l'hypothèse d'indépendance génétique des loci $\alpha$-La et $\beta$-Lg

\begin{tabular}{|c|c|c|c|c|}
\hline \multirow{2}{*}{$\alpha-\mathrm{La}$} & \multicolumn{3}{|c|}{$\beta-\mathrm{Lg}$} & \multirow{2}{*}{ Total } \\
\hline & $\mathrm{A} / \mathrm{A}$ & $\mathrm{A} / \mathrm{B}$ & $\mathrm{B} / \mathrm{B}$ & \\
\hline $\mathrm{A} / \mathrm{A}$ & ${ }_{35}^{37}$ & $\begin{array}{l}219 \\
\quad 221\end{array}$ & ${ }_{277}^{277}$ & $\begin{array}{l}533 \\
\quad(541)\end{array}$ \\
\hline $\mathrm{A} / \mathrm{B}$ & $\begin{array}{c}14 \\
15\end{array}$ & $97 \quad 96$ & ${ }_{120}^{120}$ & $\begin{array}{l}231 \\
\quad(215)\end{array}$ \\
\hline $\mathrm{B} / \mathrm{B}$ & $-_{1}$ & $\begin{array}{ll}6 & \\
& 6\end{array}$ & ${ }^{8} 7$ & 14 \\
\hline Total & $\begin{array}{l}51 \\
(58)\end{array}$ & $\begin{array}{l}322 \\
\quad(308)\end{array}$ & $\begin{array}{l}405 \\
\quad(412)\end{array}$ & 778 \\
\hline
\end{tabular}

I. 3. Relations génétiques entre les loci $\alpha_{s_{1}}-C n, \beta-C n$ et $x-C n$.

Le tableau 4 donne la répartition des 586 vaches zébus de notre échantillon en fonction de leur génotype aux loci $\alpha_{s_{1}}$ Cn et $\beta$-Cn. Contrairement à ce qui s'observe dans les races bovines françaises, où la combinaison allélique $\alpha_{s_{1}}-C_{n}{ }^{2}-\beta-C_{n} A^{*}$ n'a pas été trouvée jusqu'ici (GROSclaUdE et al., I972 c; Groscraude, 1974) on note, chez le Zébu malgache, la coexistence des combinaisons $\alpha_{s_{\mathrm{i}}}-\mathrm{Cn}_{\mathrm{B}}^{\mathrm{B}}-\beta-\mathrm{Cn}^{\mathrm{A}^{1}}$ et $\alpha_{81}-\mathrm{Cn}-\beta-\mathrm{Cn}^{\mathrm{A}^{1}}$. Le tableau I donne les fréquences, dans l'échantillon, des combinaisons alléliques de l'unité génétique $\alpha_{s_{1}} \mathrm{Cn}-\beta-\mathrm{Cn}-x-\mathrm{Cn}$, calculées par la méthode itérative de CEPPEI,INI et al. (I956).

Du fait de l'existence de la combinaison $\alpha_{s_{1}}-\mathrm{Cn}^{\mathrm{C}}-\beta-\mathrm{Cn}^{\mathrm{A}^{1}}$, le déséquilibre de linkage est donc moins flagrant chez le Zébu malgache que dans les races bovines françaises. La méthode d'analyse de HILL (I974) donne sur ce point les résultats suivants :

- entre les allèles des loci $\alpha_{s_{1}}-\mathrm{Cn}$ et $\beta-\mathrm{Cn}$ :

$\mathrm{D}=f_{\mathrm{BA}^{1}} f_{\mathrm{CA}^{2}}-f_{\mathrm{BA}^{2}} f_{\mathrm{CA}^{1}}=+$ o,0I05

avec $k=5,2$ (significatif : $\mathrm{P}<0,05$ ) 
- entre les allèles des loci $\alpha_{s_{1}}$ - $\mathrm{Cn}$ et $x$-Cn :

$\mathrm{D}=f_{\mathrm{BA}} f_{\mathrm{CB}}-f_{\mathrm{BB}} f_{\mathrm{CA}}=-0,027 \mathrm{I}$

avec $k=\mathbf{I} 6,4$ (significatif : $\mathbf{P}<0,0 \mathrm{I}$ )

- entre les allèles des loci $\beta$-Cn et $x-\mathrm{Cn}$ :

$\mathrm{D}=f_{\mathrm{A}^{1} \mathrm{~A}} f_{\mathrm{A}^{2} \mathrm{~B}}-f_{\mathrm{A}^{1} \mathrm{~B}} f_{\mathrm{A}^{2} \mathrm{~A}}=-0,0042$

avec $k=0,6$ (non significatif)

TABLEAU 4

Répartition de 586 vaches zébu en fonction de leur génotype aux loci $\alpha_{s_{1}}-C n$ et $\beta-C n$

Entre parenthèses : nombres attendus dans l'hypothèse d'équilibre génétique ; en italiques : nombres attendus dans l'hypothèse d'indépendance génétique

des loci $\alpha_{81}$-Cn et $\beta$-Cn

\begin{tabular}{|c|c|c|c|c|}
\hline \multirow{2}{*}{$\alpha_{s_{1}}-\mathrm{Cn}$} & \multicolumn{3}{|c|}{$\beta-C n$} & \multirow{2}{*}{ Total } \\
\hline & $\mathrm{A}^{1} / \mathrm{A}^{1}$ & $\mathrm{~A}^{1} / \mathrm{A}^{2}$ & $\mathrm{~A}^{2} / \mathrm{A}^{2}$ & \\
\hline $\mathrm{B} / \mathrm{B}$ & - & $\begin{array}{ll}5 & \\
& 3\end{array}$ & ${ }^{12} 13$ & 17 \\
\hline $\mathrm{B} / \mathrm{C}$ & $\begin{array}{l}32 \\
\end{array}$ & 35 & ${ }_{132}^{122}$ & $\begin{array}{l}160 \\
\quad(162)\end{array}$ \\
\hline $\mathrm{C} / \mathrm{C}$ & 3 & ${ }^{64} 73$ & $\begin{array}{l}342 \\
\quad 331\end{array}$ & $\begin{array}{l}409 \\
\quad(408)\end{array}$ \\
\hline Total & ${ }^{6}$ & $\begin{array}{l}104 \\
(104)\end{array}$ & $\begin{array}{l}476 \\
\quad(476)\end{array}$ & 586 \\
\hline
\end{tabular}

On peut donc déceler un déséquilibre de linkage entre les allèles des loci $\alpha_{s_{1}}$ - $\mathrm{Cn}$ et $\beta$-Cn d'une part, et $\alpha_{s_{1}}$-Cn et $x$-Cn, d'autre part. Cependant, si on se base sur 1'ensemble des 3 valeurs de $k$ obtenues, le déséquilibre apparaît de manière générale moins accusé dans cette population que dans les races françaises où nous avons effectué les mêmes tests (GROSCLAUDE, I974). On notera par ailleurs qu'en ce qui concerne le couple $\alpha_{s_{1}}-\mathrm{Cn}, \beta-\mathrm{Cn}$, le déséquilibre de linkage se traduit, en définitive, par une sous-représentation de la combinaison allélique $\alpha_{s_{1}}-\mathrm{Cn}^{\mathrm{C}}-\beta-\mathrm{Cn}^{\mathrm{A}^{1}}$, observation à rapprocher du fait que c'est cette combinaison qui n'a pas été trouvée jusqu'ici dans les races bovines françaises. Il est donc logique de considérer $\alpha_{s_{1}}-\mathrm{Cn}^{\mathrm{C}}-\beta-\mathrm{Cn}^{\mathbf{A}^{\mathbf{1}}}$ comme la combinaison recombinante.

On notera cependant et c'est là un point capital que les conclusions de cette discussion ne restent valables que si les variants $\alpha_{s_{1}} \mathrm{C}$ et $\beta$ - $\mathrm{A}^{1}$ contrôlés par la combinaison $\alpha_{s_{1}}-\mathrm{Cn}^{\mathrm{c}}-\beta-\mathrm{Cn}^{\mathrm{A}^{1}}$ sont identiques aux variants contrôlés par les combinaisons $\alpha_{s_{1}}-\mathrm{Cn}^{\mathrm{B}}-\beta-\mathrm{Cn}^{\mathrm{A}^{1}}$ et $\alpha_{s_{1}}-\mathrm{Cn}^{\mathrm{C}}-\beta-\mathrm{Cn}^{\mathrm{A}^{2}}$. Nous avons vérifié cette identité, qui ressort des résultats exposés dans le paragraphe suivant. 


\section{2. - Caractérisation des altérations qui différencient les variants électrophorétiques des caséines $\alpha_{s_{1}}, \beta$ et $x$ de zébu}

\section{I. Variants $\alpha_{s_{1}}-\mathrm{B}$ et $\alpha_{s_{1}}-\mathrm{C}$ contrôlés par les combinaisons alléliques classiques.}

La caséine $\alpha_{s_{1}}-\mathrm{B}$ a été préparée à partir du lait d'une femelle zébu homozygote pour l'allèle $\alpha_{s_{1}}-\mathrm{Cn}^{\mathrm{B}}$, mais hétérozygote aux loci $\beta-\mathrm{Cn}$ et $x-\mathrm{Cn}\left(\beta-\mathrm{Cn}^{\mathrm{A}^{1}} / \beta-\mathrm{Cn}^{\mathrm{A}^{8}}\right.$ et $\left.x-\mathrm{Cn}^{\mathrm{A}} / x-\mathrm{Cn}^{\mathrm{B}}\right)$, et la caséine $\alpha_{s_{1}} \mathrm{C}$ à partir du lait d'un sujet homozygote pour la combinaison $\alpha_{s_{1}}-\mathrm{Cn} \mathrm{C}-\beta-\mathrm{Cn}^{\mathrm{A}^{2}}-x-\mathrm{Cn}^{\mathrm{A}}$.

Nous avons montré précédemment que, chez les bovins, les variants $\alpha_{s_{1}}$-B et $\boldsymbol{\alpha}_{\boldsymbol{s}_{1}}$-C diffèrent par une substitution d'acides aminés située dans la partie COOHterminale de la chaîne polypeptidique de la caséine [substitution I92 Glu $\left(\alpha_{s_{1}}-\mathrm{B}\right) \rightarrow$ Gly $\left.\left(\alpha_{s_{1}}-\mathrm{C}\right)\right]$; après hydrolyse trypsique de la caséine $\alpha_{s_{1}}$ maléylée, le peptide $\mathrm{COOH}$-terminal, $\alpha_{s_{1}}$-Tm2, peut être obtenu par chromatographie sur colonne de résine Dowex $\mathrm{AG} 50 \mathrm{WX} 2$, par simple élution à 1'aide du premier tampon, de pH 3,I (GROSClAUde et al., I970 a). Nous avons donc recherché, en suivant un protocole strictement identique dans les deux cas, si les variants $\alpha_{s_{1}}$-B et $\alpha_{s_{1}}$ C du zébu se différenciaient par la même substitution.

Soixante $\mu$ Moles de caséine $\alpha_{s_{1}}$ préalablement maléylée ont été hydrolysées par la trypsine $\left(\mathrm{E} / \mathrm{S}: \mathrm{I} / 50 ; 40^{\circ} \mathrm{C}\right.$; I heure $\left.30 ; \mathrm{pH} 8,0\right)$; 1'hydrolysat ainsi obtenu a été ensuite chromatographié, après démaléylation, sur colonne de Dowex AG 50 WX 2. Le peptide $\alpha_{s_{1}}$-Tm2, obtenu par élution à l'aide du tampon de $\mathrm{pH}$ 3, I, a été repurifié par chromatographie sur colonne de Sephadex G-25 en milieu acide acétique 30 vol. p. Ioo.

La composition en acides aminés des peptides $\alpha_{s_{1}}$ - B Tm2 et $\alpha_{s_{1}}$ - CTm 2 de zébu s'est avérée identique à celle des peptides homologues bovins, la différence entre ces deux peptides ne portant que sur la teneur en glycine et en acide glutamique ( $4 \mathrm{Glx}$ et 4 Gly dans $\alpha_{s_{1}}$-CTm2, 5 Glx et 3 Gly dans $\alpha_{s_{1}}$-BTm2).

Vingt $\mu$ Moles de chacun de ces deux peptides ont alors été hydrolysées par la trypsine $\left(\mathrm{E} / \mathrm{S}: \mathrm{I} / \mathrm{IOO} ; 40^{\circ} \mathrm{C}\right.$, 3 heures ; $\mathrm{p} \mathrm{H} \mathrm{8,6)}$ puis par la thermolysine $(\mathrm{E} / \mathrm{S}: \mathrm{I} / 200$; $40^{\circ} \mathrm{C}$; I heure; $\left.\mathrm{pH} 8,6\right)$; les hydrolysats ainsi obtenus, ont ensuite été chromatographiés sur colonne de Sephadex G-I5 en milieu acide acétique 30 vol. p. Ioo. Le second pic, qui est aussi le plus important du chromatogramme, contient, entre autres, un peptide de migration rapide en électrophorèse, à $\mathrm{pH}$ I,9. Ce peptide, $\alpha_{s_{1}} \operatorname{Tm}_{2} \mathrm{~T}_{1} T^{\mathrm{T}} 4$, repurifié par électrophorèse préparative sur papier, et dont la composition est donnée dans le tableau 5 , ne peut correspondre qu'à l'élément de séquence de la caséine $\alpha_{s_{1}}$ qui comprend les résidus I86 à I93 inclus. L'action des carboxypeptidases $\mathrm{B}$ et $\mathrm{A}$ (tabl. 5) montre que chez les zébus comme chez les bovins, les variants $\alpha_{s_{1}}$-B et $\alpha_{s_{1}}$-C diffèrent par une substitution I92 Glu $\left(\alpha_{s_{1}}-\mathrm{B}\right) \rightarrow$ Gly $\left(\alpha_{s_{1}}\right.$-C).

\section{2. Variants $\beta A^{1}$ et $\beta A^{2}$ contrôlés par les combinaisons alléliques classiques.}

Aucun des II échantillons de caséine entière de zébu malgache dont nous disposions en quantités importantes n'étant du type homozygote pour $\beta A^{1}$, nous avons été amenés à opérer sur une caséine de type hétérozygote, $\beta \mathrm{A}^{1} / \mathrm{A}^{2}$, préparée par chromatographie sur colonne de $\mathrm{DEAE}$-cellulose, à partir de la même caséine entière que la caséine $\alpha_{s_{1}}$-B. 


\section{Caséine $\alpha_{\delta 1}$}

- Peptide $\alpha_{s_{1}}$ BTm2T1Th4 Composition en acides aminés

Carboxypeptidases B et A Séquence bovine homologue (résidus 186-193)

- Peptide $\alpha_{s_{1}}$ CTm2T1Th4 Composition en acides aminés Asx, 0,96 (1) ; Ser, 1,65 (2) ; Glx, 1,12 (1) ; Gly, 2,00 (2) ; lle, 0,88 (1) ; Carboxypeptidases $\mathrm{B}$ et $\mathrm{A}$ Séquence bovine homologue (résidus 186-193)

\section{Caséine $\beta$}

\section{- Peptide $\beta A^{2} C N 1 T 4$}

Composition en acides aminés Asx, 1,00 (1); Thr, 089 (1); Ser, 0,92 (1); Glx, 2,10 (2); Pro, 4,40 (5); Gly, $1,00(1)$; Ala, $0,97(1)$; Val, $0,97(1)$; lle, 1,59 (2) ; Leu, 1,03 (1) ; Tyr, 0,54 (1); Phe, 1,76 (2); His, 0,73 (1).

Leucine aminopeptidase Carboxypeptidase A Séquence bovine homologue (résidus 49-68)

\section{- Peptide $\beta A^{1} C N 1 T m 2 T h 2 d$}

Composition en acides aminés

Carboxypeptidase A

Séquence bovine homologue (résidus 59-68)

\section{- Peptide $\beta$ BT14a}

Composition en acides aminés

\section{- Peptide $\beta D T 6 a$}

Composition en acides aminés

Carboxypeptidases B et A

- Peptide $\beta D T 6 a P a T 2$

Composition en acides aminés

Casboxypeptidases $\mathrm{B}$ et $\mathrm{A}$

- Peptide $\beta D T 6 a P a T 5$

Composition en acides aminés
Asx, 1,00 (1) ; Ser, 1,61 (2) ; Glx, 2,07 (1) ; Gly, 0,89 (1) ; lle, 0,82 (1) ; Lys, 0,89 (1).

(CPB : $2 \mu l ; 16$ h) (CPA : $2 \mu l ; 20$ h) Lys, 0,$78 ;$ Glu, 0,88 .

lle-Gly-Ser-Glu-Asn-Ser-Glu-Lys. Lys, $0,94(1)$.

(CPB : $2 \mu l ; 24$ h) (CPA : $2 \mu l ; 24$ h) Lys, 0,76 ; Gly, 049 ; Ser, $0,29$. lle-Gly-Ser-Glu-Asn-Ser-Gly-Lys
$(5 \mu l ; 24 \mathrm{~h})$ 一

lle-His-Pro-Phe-Ala-Gln-Thr-Gln-Ser-Leu-Val-Tyr-Pro-Phe-Pro-GlyPro-lle-Pro-Asn.

Asx, 1,20 (1) ; Pro, 2,64 (3) ; Gly, 0,92 (1) ; Val, 0,72 (1) ; lle, 1,08 (1) ; Tyr, 0,48 (1) ; Phe, 0,76 (1) ; His, 0,80 (1).

$(5 \mu l ; 24$ h) Asn, 0,63 ; His, 0,56 .

Val-Tyr-Pro-Phe-Pro-Gly-Pro-lle-His-Asn.

Thr, 0, 93 (1) ; Glx, 2,05 (2) ; Pro, 1,99 (2) ; Val, 0,97 (1) ; Tyr, 0,66 (1) ; Phe, 1,00 (1) ; Arg, 0,99 (1).

Asx, 2,00 (1-2); Thr, 1,59 (1-2); Ser, 3,58 (4); Glx, 6,89 (7) ; Pro, 2,10 (1-2) ; Gly, 1,58 (1) ; Val, 1,89 (2); lle, 1,89 (2); Leu, 2,32 (3) ; Lys, 1,02 (1) ; Arg, 0,84 (1).

(CPB : $2 \mu \mathrm{l} ; 20 \mathrm{~h}$ ) (CPA : $2 \mu \mathrm{l} ; 20 \mathrm{~h}$ ). Thr, 0,40 ; Ser, 0,26; Gly, 0,32 ; lle, 0,44 ; Arg, 0,82 .

Asx, 1,09 (1) ; Ser, 2,12 (2) ; Glx, 2,90 (3-5) ; Pro, 1,46 (1) ; Gly, 0,93 (1) ; Val, 1,31 (2) ; lle, 0,71 (1) ; Leu, 2,03 (2); Lys, 0,65 (1).

(CPA : $2 \mu \mathrm{l} ; \mathrm{CPB}: 2 \mu \mathrm{l} ; 40^{\circ} \mathrm{C} ; 18$ heures ; pH 8,5) Lys, 1,00 ; Ser, 1,56 ; Leu, 0,94 .

Thr, 0,75 (1) ; Ser, 1,33 (2); Glx, 1,29 (1-2) ; lle, 1,00 (1) ; Arg, 1,25 (1).

Les travaux précédemment effectués par notre équipe sur la caséine $\beta$ bovine avaient porté, entre autres, sur les peptides obtenus par hydrolyse de cette caséine par le bromure de cyanogène : le site de la substitution d'acides aminés différenciant les variants $\beta \mathrm{A}^{1}$ et $\beta \mathrm{A}^{2}$ [substitution 67 Pro $\left(\beta \mathrm{A}^{2}\right) \rightarrow$ His $\left(\beta \mathrm{A}^{1}\right)$ ] avait été localisé 
dans le peptide $\mathrm{NH}_{2}$-terminal, $\beta$-CNI, qui comporte 93 résidus d'acides aminés (GrosclaUde et al., I972 a). Ce peptide peut être obtenu facilement, soit par simple dialyse de l'hydrolysat $\mathrm{CNBr}$, soit par chromatographie de cet hydrolysat sur colonne de Sephadex G-5o en milieu acide ; on le trouve alors dans le premier pic du chromatogramme (RIBADEAU-Dumas et al., I970).

Nous avons, dans un premier temps, vérifié par électrophorèse en gel d'amidon avec urée, à $\mathrm{pH} 3,0$, que la fraction $\beta \mathrm{A}^{1} / \mathrm{A}^{2} \mathrm{CNI}$ de zébu contenait deux peptides dont la mobilité électrophorétique était celle des peptides bovins $\beta \mathrm{A}^{1} \mathrm{CNI}$ et $\beta \mathrm{A}^{2} \mathrm{CNI}$. Ce résultat conduisait donc à rechercher, chez le Zébu également, la substitution différenciant $\beta \mathrm{A}^{1}$ et $\beta \mathrm{A}^{2}$ dans le peptide $\mathrm{CNI}$.

Environ $30 \mu$ Moles du peptide $\beta \mathrm{A}^{1} / \mathrm{A}^{2} \mathrm{CNI}$ de zébu ont alors été hydrolysées par la trypsine $\left(\mathrm{E} / \mathrm{S}: \mathrm{I} / \mathrm{IOO} ; 40^{\circ} \mathrm{C} ; 3\right.$ heures; $\left.\mathrm{pH} 8\right)$, et 1'hydrolysat ainsi obtenu a été chromatographié sur colonne de Dowex AG 50 WX 2 selon un protocole expérimental identique à celui qui avait été suivi pour l'étude du peptide $\beta \mathrm{A}^{2} \mathrm{CNI}$ bovin (RIBADEAU-Dumas et al., I97I). Les peptides figurant dans les différentes fractions de cette chromatographie ont été repurifiés par électrophorèse ou chromatographie préparative sur papier : leur composition en acides aminés s'est avérée identique à celle des peptides homologues de $\beta A^{2}$, y compris celle du peptide $\beta A^{2} \mathrm{CNIT}_{4}$ formé des résidus 49 à 68 inclus, qui comprend, chez les bovins le site de la substitution $\beta A^{2} \rightarrow \beta A^{1}$ (position 67 ). Par contre, le peptide homologue de ce dernier dans $\beta A^{1} n^{\prime} a$ pu être retrouvé dans cette chromatographie.

Pour retrouver ce dernier peptide, $5 \mu$ Moles du peptide $\beta \mathrm{A}^{1} / \mathrm{A}^{2} \mathrm{CNI}$ de zébu ont été hydrolysées par la trypsine $\left(\mathrm{E} / \mathrm{S}: \mathrm{I} / 50 ;\right.$ I heure; $\left.40^{\circ} \mathrm{C} ; \mathrm{pH} 8,0\right)$ après maléylation (GROSCLAUDE et al., I970). L'hydrolysat ainsi obtenu a ensuite été chromatographié, après démaléylation, sur colonne de Sephadex G-5o en milieu acide acétique 30 vol. p. IOo. La seconde fraction du chromatogramme contenait essentiellement un peptide, $\beta \mathrm{A}^{1} / \mathrm{A}^{2} \mathrm{CNI} T \mathrm{Tm} 2$, donnant au réactif de Pauly une coloration indiquant la présence de tyrosine et d'histidine. Cette fraction a alors été hydrolysée par la thermolysine, (E/S : I/50; I heure; $40^{\circ} \mathrm{C} ; \mathrm{pH}$ ), et 1 'hydrolysat ainsi obtenu, chromatographié sur colonne de Sephadex G-25 en milieu acide acétique 30 vol. p. I0o. La seconde fraction du chromatogramme contenait entre autres, un peptide colorable au réactif de Pauly (présence d'histidine et tyrosine), qui a été séparé par électrophorèse préparative sur papier à $\mathrm{pH}$ I,9. La composition de ce peptide, $\beta \mathrm{A}^{1} \mathrm{CNITm} 2 \mathrm{Th} 2 \mathrm{~d}$, donnée dans le tableau 5 , est celle du segment 59 à 68 dans la séquence de la caséine $\beta \mathrm{A}^{1}$ bovine ; 1'action de la carboxypeptidase $A$ (tabl. 5) confirme la présence d'un résidu histidyle en avant-dernière position. Ces résultats indiquent donc bien que les variants $\beta \mathrm{A}^{1}$ et $\beta \mathrm{A}^{2}$ diffèrent chez le Zébu par la même substitution, 67 Pro $\left(\beta A^{2}\right) \rightarrow$ His $\left(\beta A^{1}\right)$, que chez les bovins.

\section{3. Variants $\alpha_{s_{1}}-C$ et $\beta A^{1}$ contrôlés par la combinaison allélique $\alpha_{s_{1}}-C n^{\mathrm{C}}-\beta-C n^{\mathrm{A}^{1}}$.}

Nous avons utilisé, pour l'étude des variants $\alpha_{s_{1}}$ C et $\beta A^{1}$ contrôlés par la combinaison allélique $\alpha_{s_{1}}-\mathrm{Cn}^{\mathrm{C}}-\beta-\mathrm{Cn}^{\mathrm{A}^{1}}$, un mélange de petits échantillons de phénotype $\alpha_{s_{1}}-\mathrm{C}, \beta \mathrm{A}^{1} / \mathrm{A}^{2}$. En effet aucun des II échantillons de caséine dont nous disposions en quantité assez importante n'était de phénotype $\alpha_{s_{1}}-\mathrm{C}, \beta \mathrm{A}^{1}$ ou $\alpha_{s_{1}}-\mathrm{C}, \beta \mathrm{A}^{1} / \mathrm{A}^{2}$; d'autre part nous disposions de trop faibles quantités de caséines de phénotype $\alpha_{s_{1}}-\mathrm{C}, \beta \mathrm{A}^{1}$ (3 petits échantillons seulement). 
La caséine $\alpha_{s_{1}}$-C a été préparée à partir de I $g$ de mélange, en quantités sensiblement égales, de 20 échantillons de " caséines entières " possédant ce phénotype. Le peptide $\alpha_{s_{1}}$-C CNITI, qui correspond au segment I52 à I93 de la chaîne polypeptidique de la caséine $\alpha_{s_{1}}$-C a été préparé en suivant, pour l'essentiel, le même protocole expérimental que celui de MERCIER et al. (I970 b).

L'hydrolyse de ce peptide par les carboxypeptidases B et A (peptide : 0,037 $\mu \mathrm{M}$ $\mathrm{CPB}: 2 \mu 1$; CPA : $2 \mu 1 ; 40^{\circ} \mathrm{C}: 3$ heures ; $\left.\mathrm{pH} 8,5\right)$ libère de la lysine $(0,98)$ et de la glycine $(0,8 \mathrm{I})$. Ceci confirme que l'allèle $\alpha_{s_{1}}-\mathrm{Cn}_{1} \mathrm{c}$ figurant dans la combinaison $\alpha_{s_{1}}-\mathrm{Cn}^{\mathrm{C}}-\beta-\mathrm{Cn}^{\mathrm{A}^{1}}$ détermine bien le variant $\alpha_{s_{1}} \mathrm{C}$ classique, caractérisé par la présence d'un résidu glycyle en position I92 de la chaîne polypeptidique.

La caséine $\beta \mathrm{A}^{1} / \mathrm{A}^{2}$ a été préparée à partir de $2 \mathrm{~g}$ d'un mélange, en quantités sensiblement égales, de Io échantillons individuels de " caséine entière ", possédant toujours le phénotype $\alpha_{s_{1}}-\mathrm{C}, \beta \mathrm{A}^{1} / \mathrm{A}^{2}$. Nous avons alors suivi pour l'analyse de cette préparation le même protocole expérimental que celui qui nous avait permis de préparer précédemment le peptide $\beta \mathrm{A}^{1} / \mathrm{A}^{2} \mathrm{CNI} T \mathrm{~T} 2{ }^{\prime} \mathrm{Th} 2 \mathrm{~d}$ (voir paragraphe 22 ).

Ce travail nous a permis d'obtenir un peptide de composition identique à celle de $\beta \mathrm{A}^{1} / \mathrm{A}^{2} \mathrm{CNITm}{ }^{\top} \mathrm{Th} 2$ (tabl. 5) et libérant également, par action de la carboxypeptidase $A$, de l'asparagine et de l'histidine. L'allèle $\beta-\mathrm{Cn}^{\mathrm{A}^{1}}$ figurant dans la combinaison allélique $\alpha_{s_{1}}-\mathrm{Cn}^{\mathrm{C}}-\beta-\mathrm{Cn}^{\mathrm{A}^{1}}$ détermine donc bien le variant $\beta \mathrm{A}^{1}$ classique, caractérisé par la présence d'un résidu histidyle en position 67 de la chaîne polypeptidique.

En conclusion, la combinaison allélique $\alpha_{s_{1}}-\mathrm{Cn}^{\mathrm{C}}-\beta-\mathrm{Cn}^{\mathrm{A}^{1}}$ peut bien être considérée comme dérivant par recombinaison des combinaisons $\alpha_{s_{1}}-\mathrm{Cn}^{\mathrm{B}}-\beta-\mathrm{Cn}^{\mathrm{A}^{1}}$ et $\alpha_{s_{1}}-\mathrm{Cn}{ }^{\mathrm{C}}-\beta-\mathrm{Cn}^{\mathrm{A}^{2}}$.

\section{4. Variants $x A$ et $x B$.}

Les investigations sur la caséine $x \mathrm{~A}$ de zébu ont été répétées - nous en verrons la raison plus loin - sur deux préparations différentes de caséine $x \mathrm{~A}_{1}$, provenant de sujets tous deux homozygotes pour la combinaison allélique $\alpha_{s_{1}}-\mathrm{Cn} \mathrm{C}-\beta-\mathrm{Cn}^{\mathrm{A}^{2}}-\chi-\mathrm{Cn}^{\mathrm{A}}$, mais élevés dans des régions différentes (région I et 3 sur la fig. I). La caséine $x B_{1}$ de Zébu a été préparée à partir du lait d'un sujet homozygote pour la combinaison allélique $\alpha_{81}-\mathrm{Cn}^{\mathrm{B}}-\beta-\mathrm{Cn}^{\mathrm{A}^{2}}-x-\mathrm{Cn}^{\mathrm{B}}$.

Chez les bovins, la différence de mobilité électrophorétique des variants $x \mathrm{~A}$ et $x \mathrm{~B}$ est due à la substitution $\mathrm{I}_{4} 8 \mathrm{Asp}(x \mathrm{~A}) \rightarrow$ Ala $(x \mathrm{~B})$, localisée dans le peptide $x \mathrm{CN} 2$, l'un des trois peptides obtenus par hydrolyse de la caséine $x$ par le bromure de cyanogène ; ce peptide représente la partie COOH-terminale de la caséine $x$, et correspond au " caséino-macropeptide " amputé de son résidu méthionyle $\mathrm{NH}_{2}-$ terminal ; les peptides $x \mathrm{~A}_{1} \mathrm{CN} 2$ et $x \mathrm{~B}_{1} \mathrm{CN}_{2}$ diffèrent en outre par une seconde substitution $\mathrm{I}_{36} \mathrm{Thr}(x \mathrm{~A}) \rightarrow$ Ile $(x \mathrm{~B})$ qui n'affecte pas, évidemment, la charge globale de la molécule (Grosclaude et al., I972 b).

Les peptides $x \mathrm{~A}_{1} \mathrm{CN} 2$ et $x \mathrm{~B}_{1} \mathrm{CN}_{2}$ de zébu ont été préparés par chromatographie sur colonne de Dowex AG 50 WX 2 selon MERCIER et al. (I972). Les compositions en acides aminés obtenues pour ces peptides n'étaient pas très satisfaisantes, mais indiquaient toutefois, que, comme chez les bovins, le peptide $x \mathrm{~A}_{1} \mathrm{CN} 2$ de zébu possède un résidu Asx de plus que le peptide $x \mathrm{~B}_{1} \mathrm{CN}_{2}$. Ce résultat nous a incités à procéder, dans un premier temps, à une étude détaillée du peptide $x \mathrm{~A}_{1} \mathrm{CN}_{2}$ de zébu. 
Ce peptide (Io $\mu$ Moles) a été hydrolysé par la thermolysine (E/S : I/200 ; I heure ; $40^{\circ} \mathrm{C} ; \mathrm{pH} 8,0$ ) et l'hydrolysat ainsi obtenu, chromatographié sur colonne de Dowex AG 50 WX 2 en suivant le même protocole que pour les bovins (MERCIER et al., I972 ; GrosclaUde et al., I972 b). Tous les peptides obtenus ont été repurifiés, soit sur colonne de Sephadex G-Io à G-25, soit par électrophorèse ou chromatographie préparative sur papier.

La première fraction du chromatogramme contenait le peptide $x \mathrm{~A}_{1} \mathrm{CN} 2 \mathrm{ThI}$ dont la composition (tab1. 6) est identique à celle du peptide $x \mathrm{~A}_{1} \mathrm{CN} 2 \mathrm{ThI}$ bovin, correspondant à l'élément de séquence formé des résidus I46 à I6I (fig. 2). Recoupé de manière plus poussée par la thermolysine, $\left(\mathrm{E} / \mathrm{S}: \mathrm{I} / 50 ; 4\right.$ heures; $\left.40^{\circ} \mathrm{C} ; \mathrm{pH} 8,5\right)$, $x \mathrm{~A}_{1} \mathrm{CN} 2 \mathrm{ThI}$ se scinde en deux peptides dont l'un, $x \mathrm{~A}_{1} \mathrm{CN} 2 \mathrm{Thra}$, de migration anodique, a été préparé par électrophorèse préparative sur papier à pH 4,7. La compo-

\section{TABLEAU 6}

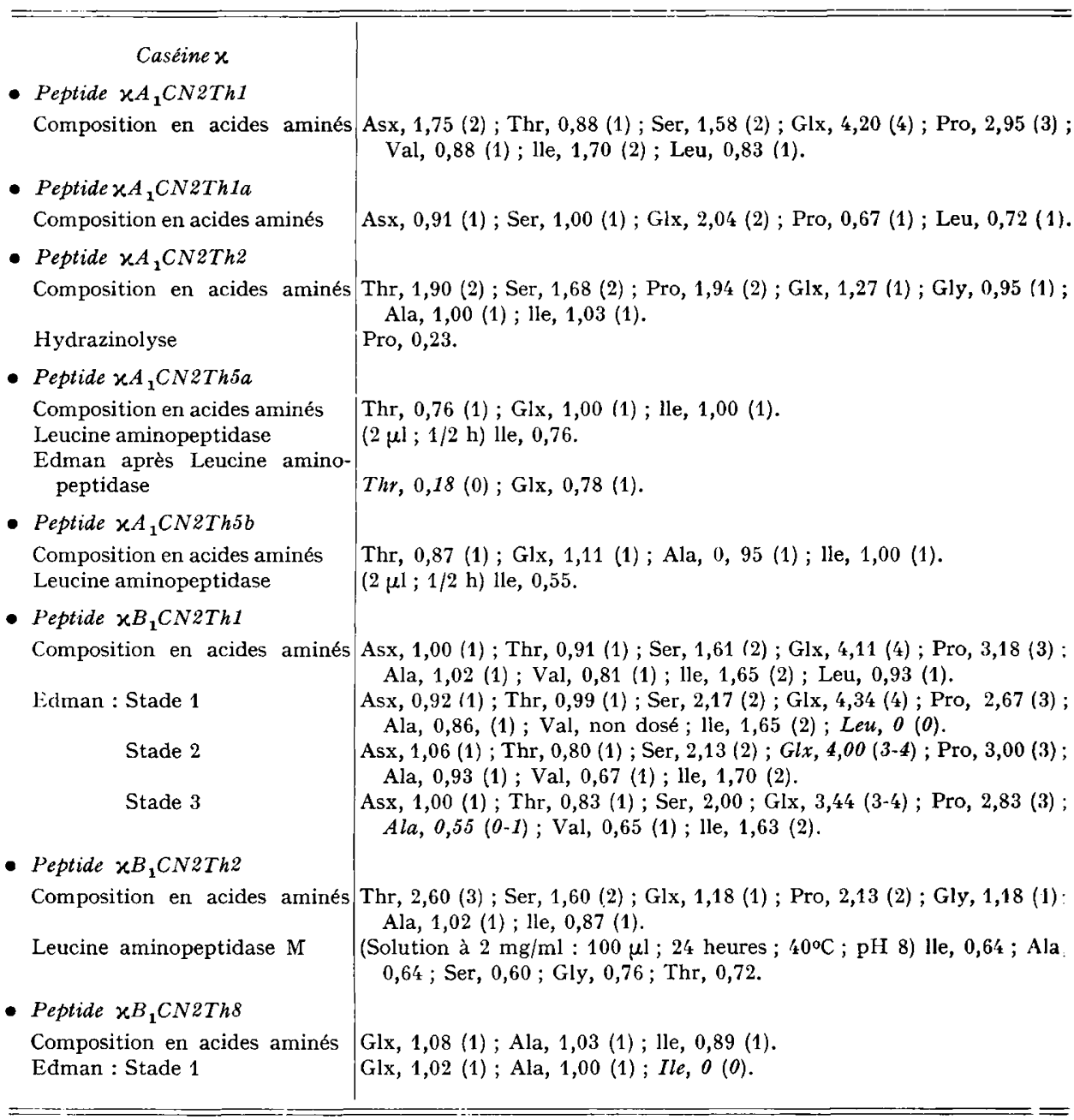


sition de ce peptide, ainsi que le fait qu'il libère de la phosphosérine par hydrolyse acide ménagée, indiquent qu'il correspond à l'élément de séquence formé des résidus I46 à I5I : ceci a été confirmé par l'établissement de sa séquence par spectrométrie de masse, après déphosphorylation.

La seconde fraction du chromatogramme contenait le peptide $x \mathrm{~A}_{1} \mathrm{CN} 2 \mathrm{Th} 2$ dont la composition (tabl. 5) correspond à celle de l'élément de séquence formé des résidus I25 à I34. La cinquième fraction nous a fourni deux peptides séparés par électrophorèse préparative sur papier à $\mathrm{pH}$ I,9, CN2Th5a et $\mathrm{CN}_{2} \mathrm{~T}$ h $5 \mathrm{~b}$, qui correspondent visiblement (tabl. 6 et fig. 2) à l'élément de séquence formé des résidus $\mathrm{I} 35$ à $\mathrm{I} 37$ pour le premier, et $\mathrm{I} 35$ à $\mathrm{I} 38$ pour le second. Toutes les autres fractions nous ont donné des peptides de composition identique à celle des peptides bovins obtenus dans les mêmes conditions, ce qui nous a permis de reconstituer le peptide $x \mathrm{~A}_{1} \mathrm{CN}_{2}$.

Thr-lle-Ala-Ser-Gly-Glu-Pro-Thr-Ser-Thr-Pro-Ile-Thr-Glu-Ala-Val-Glu-Ser-Thr-Val-

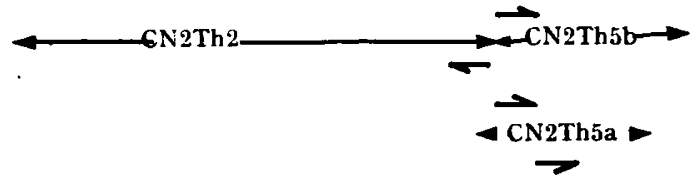

145 150 155 160

Ala-Thr-Leu-Glu-Asp-Ser-Pro-Glu-Val-lle-Glu-Ser-Pro-Pro-Glu-lle-Asn-Thr-Val-Gln ... $\mathbf{p}$

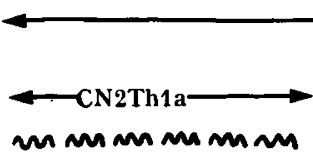

FIG. 2. - Élément de la struccure primaire du caséino-macropeptide du variant $x \mathrm{~A}$ de zébu Les différences observées avec le variant $\chi B$ de zébu sont indiquées en italiques : peptide cité dans le texte $; \longrightarrow$ : acide aminé libéré par la leucine aminopeptidase : acide aminé identifié par la technique soustractive d'Edman; - acide aminé identifié par hydrazinolyse $; m$ : séquence établie par spectrometrie de masse

En définitive, ces résultats prouvaient que le variant $x \mathrm{~A}$ de zébu comportait bien, comme son homologue bovin, un résidu aspartyle en position 148 ; mais ils révélaient aussi qu'un résidu isoleucyle se trouvait en position $\mathrm{I} 35$ dans le variant $x A$ de zébu que nous avons étudié, au lieu d'un résidu thréonyle dans les variants $x \mathrm{~A}$ et $x \mathrm{~B}$ bovins. Cette dernière observation pouvait paraître troublante, quand on la rapprochait du fait que les variants $x \mathrm{~A}$ et $x \mathrm{~B}$ bovins diffèrent, outre la substitution I48 Asp $(x \mathrm{~A}) \rightarrow \mathrm{Ala}(x \mathrm{~B})$ par une substitution I36 Thr $(x \mathrm{~A}) \rightarrow 11 \mathrm{e}(x \mathrm{~B})$. Nous avons donc répété cette partie de notre travail sur un second échantillon de caséine $x \mathrm{~A}_{1}$ de zébu, provenant d'un lait prélevé dans une toute autre région que le précédent : les résultats obtenus sur ce second échantillon confirment en tous points les précédents. 
L'étude du peptide $x \mathrm{~B}_{1} \mathrm{CN} 2$, menée selon un protocole expérimental identique au précédent, nous a notamment permis d'obtenir les peptides suivants :

- le peptide $\chi \mathrm{B}_{1} \mathrm{CN} 2 \mathrm{Th}$, dont la composition (tab1. 6) correspond à celle de l'élément de séquence formé des résidus I46 à I6r. Comme l'indiquent les résultats de la dégradation soustractive d'Edman, le troisième résidu â partir de l'extrémité $\mathrm{NH}_{2}$-terminale de ce peptide (position $\mathrm{I}_{4} 8$ dans la chaîne polypeptidique) est un résidu alanyle, au lieu d'un résidu aspartyle dans le variant $x \mathrm{~A}$ bovin (GROSCLAUDE et al., I972 b) ou zébu (ci-dessus).

- les peptides $x \mathrm{~B}_{1} \mathrm{CN} 2 \mathrm{Th} 2$ et $x \mathrm{~B}_{1} \mathrm{CN} 2 \mathrm{Th} 8$, qui correspondent respectivement aux éléments de séquence formés des résidus $\mathrm{I} 25$ à $\mathrm{I} 35$ et I36 à I38. L'action de la LAP M sur $x \mathrm{~B}_{1} \mathrm{CN} 2$ Th2 confirme que le résidu 135 est un résidu thréonyle ; un stade de dégradation soustractive d'Edman montre qu'un résidu isoleucyle se trouve en position $\mathrm{NH}_{2}$-terminale dans $x \mathrm{~B}_{1} \mathrm{CN} 2$ Th8

De manière générale, l'ensemble des résultats obtenus sur le peptide $x \mathrm{~B}_{1} \mathrm{CN} 2$ de zébu ne permet de déceler aucune différence avec son homologue bovin.

... Thr-lle-Ala-Ser-Gly-Glu-Pro-Thr-Ser-Thr-Pro-Thr-Ile-Glu-Ala-Val-Glu-Ser-Thr-Val-

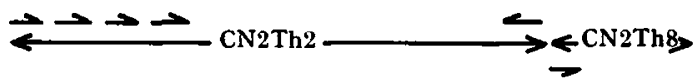

Ala-Thr-Leu-Glu-Ala-Ser-Pro-Glu-Val-lle-Glu-Ser-Pro-Pro-Glu-lle-Asn-Thr-Val-Gln ...

!

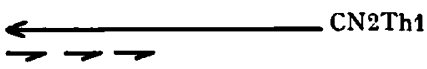

FIG. 3. - Élement de la structure primaire du caséino-macropeptide du variant $x B$ de zébu

Les différences observées avec le variant $\chi A$ de zébu sont indiquées en italiques

$\leftrightarrow$ : peptide cité dans le texte $\rightarrow$ et $\longrightarrow \quad$ : acide aminé libéré par la leucine aminopeptidase $M$;

- : acide aminé identifié par la technique soustractive d'Edman

En définitive la différence de charge nette entre les variants $x \mathrm{~A}$ et $x \mathrm{~B}$ est donc imputable, chez le Zébu comme chez les bovins, à une substitution I48 Asp $(x \mathrm{~A}) \rightarrow$ Ala $(x \mathrm{~B})$. Par ailleurs, comme chez les bovins, les caséinomacropeptides des variants $x \mathrm{~A}$ et $x \mathrm{~B}$ de zébu diffèrent par une seconde substitution, I36 Thr $(x \mathrm{~A}) \rightarrow$ lle $(x \mathrm{~B})$ qui n'affecte pas la charge globale de ces variants. Mais en outre, nous avons décelé, entre les caséino-macropeptides des variants $x A$ et $x \mathrm{~B}$ de zébu une troisième substitution, I35 lle $(x \mathrm{~A}) \rightarrow$ Thr $(x \mathrm{~B})$, également sans effet sur la charge globale, et qui n'a pas été signalée jusqu'à présent chez les bovins.

\section{5. Variant $\beta B$.}

Absent dans notre échantillon de population de zébus malgaches, le variant $\beta B$ a été préparé à partir du lait d'une vache zébu de race Choa, provenant de la Répu- 
blique tchadienne (GROSCLAUDE et QUEVAL, I973), homozygote pour la combinaison allélique $\alpha_{s_{1}}-\mathrm{Cn}^{\mathrm{B}}-\beta-\mathrm{Cn}^{\mathrm{B}}-x-\mathrm{Cn}^{\mathrm{A}}$.

Nous avons établi précédemment que, chez les bovins, le variant $\beta B$ différait $\mathrm{du}$ variant $\beta \mathrm{A}^{1}$ par la substitution $\mathrm{I22} \operatorname{Ser}\left(\beta \mathrm{A}^{1}\right) \rightarrow \operatorname{Arg}(\beta \mathrm{B})$ (GROScLAUDE et al., I972 $a$ ). Cette substitution se traduit, en particulier, par l'apparition, dans les fingerprints trypsiques de $\beta B$, d'un peptide supplémentaire qui réagit avec la ninhydrine en donnant une coloration brune très caractéristique (BRIGNON et al., I97I). Ce peptide ( $\beta \mathrm{B}_{\text {T }} 4 a$ ), correspond dans la chaîne polypeptidique de la caséine $\beta \mathrm{B}$ bovine aux résidus II4 à I22.

Environ ro $\mu$ Moles de caséine $\beta B$ de zébu ont été hydrolysées par la trypsine $\left(\mathrm{E} / \mathrm{S}: \mathrm{I} / \mathrm{IOO} ; 40^{\circ} \mathrm{C} ; 2\right.$ heures; $\left.\mathrm{pH} 7,8\right)$. Le fingerprint de cet hydrolysat révélant la présence, après coloration à la ninhydrine, d'un peptide brun occupant la même position que le peptide bovin $\beta$ BTI $4 \mathrm{a}$, la totalité de l'hydrolysat a été chromatographié sur une colonne de Sephadex G-50 en milieu acide acétique 30 vol. p. Ioo. Le peptide brun qui se retrouve dans la quatrième fraction du chromatogramme a été repurifié par une chromatographie préparative sur papier, suivie d'une électrophorèse préparative sur papier à $\mathrm{pH} \mathrm{I,9} \mathrm{(4500} \mathrm{volts;} 20 \mathrm{mn})$. Sa composition en acides aminés, donnée dans le tableau 5 est identique à celle du peptide bovin $\beta B$ Tr $4 \mathrm{a}$, ce qui prouve que, chez le Zébu, le variant $\beta B$ diffère du variant $\beta \mathrm{A}^{\mathbf{1}}$, par la même substitution que chez les bovins $\left[\mathrm{I}_{22} \operatorname{Ser}\left(\beta \mathrm{A}^{1}\right) \rightarrow \operatorname{Arg}(\beta \mathrm{B})\right]$.

\section{6. Variant $\beta D$.}

Absent, comme $\beta \mathrm{D}$, de notre échantillon de population de zébus malgaches, le variant $\beta \mathrm{D}$ a été préparé à partir de deux petits échantillons de lait $(30 \mathrm{ml}$ chacun) provenant de métis yak $\times$ zébu népalais, de génotype $\alpha_{s_{1}}-\mathrm{Cn}^{\mathrm{C}} / \alpha_{s_{1}}-\mathrm{Cn}^{\mathrm{c}}$, $\beta-\mathrm{Cn}^{\mathrm{A}^{2}} / \beta-\mathrm{Cn}^{\mathrm{D}}$ et $x-\mathrm{Cn}^{\mathrm{A}} / x-\mathrm{Cn}^{\mathrm{A}}$; dans ces deux génotypes, l'allèle $\beta-\mathrm{Cn}^{\mathrm{D}}$ est d'origine zébu (Grosclaude et al., I974 $a$ ). La caséine $\beta D$ a été purifiée, à partir du mélange $\beta A^{2} D$, par une simple chromatographie sur colonne de DEAE-cellulose (MERCIER et al., I968), avec la même facilité qu'à partir du mélange $\beta B D$ (THOMPSON et al., I969).

Thompson et al. (1969) ont donné, du variant $\beta \mathrm{D}$, une composition en acides aminés et en phosphore que nous avons interprétée d'une autre manière que ne l'ont fait ces auteurs : nous avons comparé $\beta D$ non pas à $\beta B$ et $\beta C$, mais à $\beta A^{2}$ : associé à $\alpha_{s_{1}}$ - $\mathrm{Cn}^{\mathrm{c}}$, l'allèle $\beta$ - $\mathrm{Cn}^{\mathrm{D}}$ nous a semblé en effet, plutôt dériver de $\beta \mathrm{A}^{2}$. Dans cette optique la composition en acides aminés donnée par THompson et al. (rg69) fait surtout apparaître que, par rapport à $\beta A^{2}, \beta D$ possède un résidu lysyle en plus et un à deux groupements phosphates en moins. Ceci incitait à rechercher dans les phosphopeptides de $\beta D$ l'altération qui différencie ce variant de $\beta A^{2}$.

Nous avons donc, à partir d'un hydrolysat de $4 \mu$ Moles de caséine $\beta D(E / S$ : $\mathrm{I} / 5 \mathrm{O} ; 40^{\circ} \mathrm{C} ; 2$ heures $\left.30 ; \mathrm{pH} 8,6\right)$ tenté de purifier les peptides trypsiques de ce variant en adoptant exactement le protocole expérimental suivi pour les peptides de la caséine $\beta$ bovine (RIBADEAU-Dumas et al., I970) et qui comporte une chromatographie sur résine Dowex AG $50 \mathrm{WX}$, suivie de repurifications, soit sur colonne de Sephadex, soit par chromatographie ou électrophorèse préparatives sur papier.

Ce travail ne nous a pas permis de retrouver tous les peptides de la caséine $\beta D$. Cependant outre les peptides de composition identique à celle des peptides bovins TI, $\mathrm{T}_{2}, \mathrm{~T}_{3} \mathrm{~A}$ (contenant également un résidu phosphoséryle dans $\beta \mathrm{D}$ ), $\mathrm{T}_{4}, \mathrm{~T}_{5}, \mathrm{~T} 6, \mathrm{~T} I \mathrm{I}$, 
TIz et TI4, nous avons obtenu, à partir de la sixième fraction de la chromatographie sur colonne de Dowex, le peptide $\beta$ DT6a, repurifié par chromatographie sur colonne de Sephadex G-25 en milieu acide acétique 30 vol. p. Ioo, et dont la composition en acides aminés est donnée dans le tableau 5 . Cette composition, ainsi que le fait que $\beta$ DT6a libère, par hydrolyse acide ménagée, plusieurs phosphosérines (moyenne de 2 mesures : 3 ,I) indiquent que ce peptide représente la partie $\mathrm{NH}_{2}$-terminale de la caséine $\beta D$ (fig. 4). Dans cette hypothèse, les teneurs obtenues pour plusieurs résidus

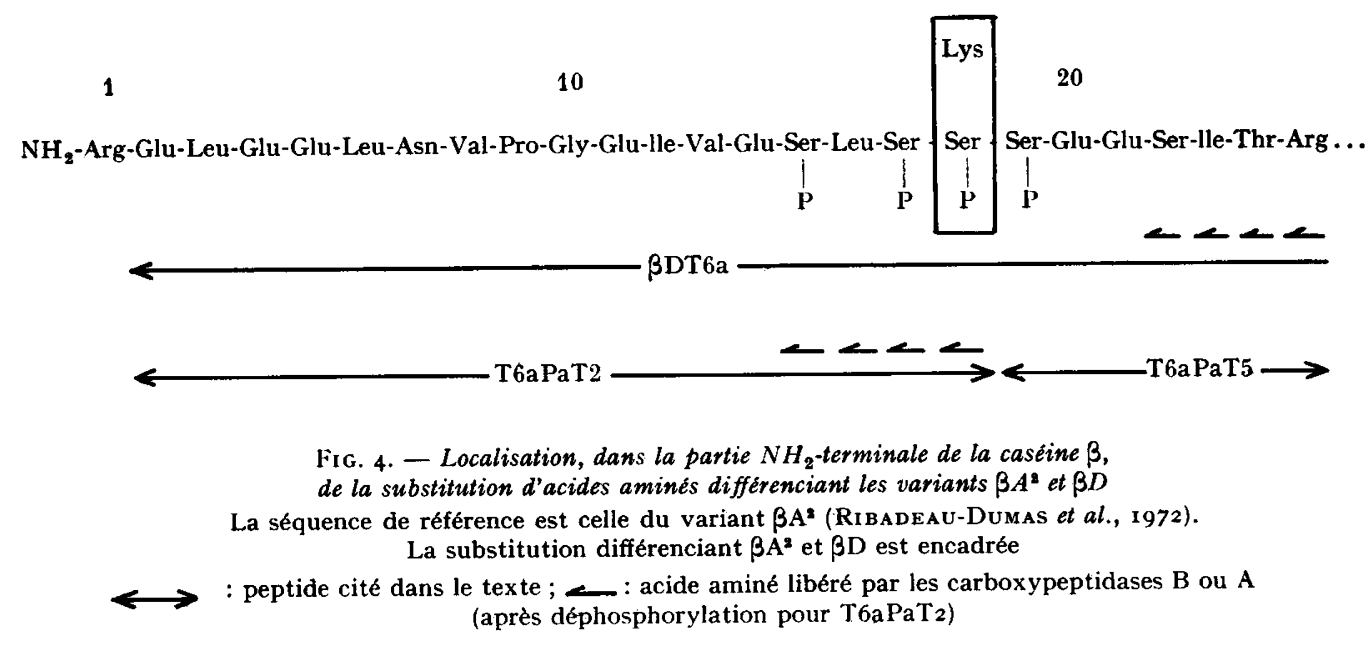

(Asx, Thr, Pro, Gly) sont cependant trop élevées, ce qui peut être dû à la présence d'une impureté, décelable par électrophorèse sur papier, mais que nous n'avons pas tenté d'éliminer, compte tenu de la faible quantité de peptide disponible. D'autre part, la présence, dans le peptide $\beta$ DT6a, d'un résidu lysyle, et l'absence, par rapport au peptide $\mathrm{NH}_{2}$-terminal bovin $\left(\beta \mathrm{A}^{2} \mathrm{TI}\right)$ d'un résidu arginyle peuvent s'interpréter a priori de plusieurs manières. Tenant compte d'observations antérieures indiquant que le résidu arginyle $\mathrm{NH}_{2}$-terminal pouvait être libéré par la trypsine (RIBADEAUDUMAs et al., I970 ; GrosclaUde et MAHE, I97I), nous avons retenu cette hypo-

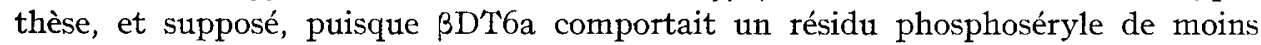
que $\beta A^{2}$ Tr , que les variants $\beta A^{2}$ et $\beta D$ différaient par une substitution Ser $P \rightarrow L y s$, se traduisant par l'introduction, dans le variant $\beta D$, d'une liaison Lys-Ser $P$, non hydrolysable par la trypsine sans déphosphorylation préalable du peptide.

Environ I $\mu$ Mole de peptide $\beta$ DT6a a donc été hydrolysée successivement par la phosphatase alcaline $\left(5 \mu 1 ; 40^{\circ} \mathrm{C} ; 24\right.$ heures; $\left.\mathrm{pH} 8,6\right)$ puis par la trypsine $\left(\mathrm{E} / \mathrm{S}: \mathrm{I} / 5^{\circ} ; 40^{\circ} \mathrm{C} ; 3\right.$ heures; $\left.\mathrm{pH} 8,6\right)$. L'électrophorèse à $\mathrm{pH} \mathrm{I}, 9$ de cet hydrolysat indique la présence de 6 fractions différentes et en quantités inégales (certaines provenant de l'impureté contaminant $\beta \mathrm{D}^{\prime} \mathrm{T} 6 \mathrm{G}$ ). La composition en acides aminés des peptides obtenus, après électrophorèse préparative, par élution de 2 fractions principales ( $\beta \mathrm{DT} 6 a \mathrm{PaT} 2$ et $\beta \mathrm{DT}^{2} a \mathrm{PaT}_{5}$ ) est donnée dans le tableau 5.

Si l'on fait abstraction du fait que les quantités d'acide glutamique trouvées pour ces peptides sont inférieures à celles qui sont attendues dans cette hypothèse, 
ces deux peptides paraissent bien résulter de 1'hydrolyse d'un peptide homologue de $\beta A^{2} \mathrm{TI}$, mais amputé du résidu arginyle $\mathrm{NH}_{2}$-terminal et comportant en position I8, un résidu lysyle au lieu du résidu séryle. L'action des carboxypeptidases $\mathrm{A}$ et $\mathrm{B}$ sur $\beta$ DT6 6 et $\beta \mathrm{DT} 6 a \mathrm{PaT} 2$ donne des résultats tendant à confirmer cette hypothèse.

Ce travail, quoique imparfait, indique donc que le variant $\beta \mathrm{D}$ diffère du variant $\beta A^{2}$ par la substitution I8 $\operatorname{PSer}\left(\beta A^{2}\right) \rightarrow$ Lys $(\beta D)$. Une telle substitution rend parfaitement compte de la mobilité électrophorétique de $\beta \mathrm{D}$, tant en milieu acide qu'en milieu alcalin; compte tenu également de la composition en acides aminés donnée par Thompson et al. (I969) il est très vraisemblable que cette substitution est seule responsable de la différence de charge globale entre $\beta \mathrm{A}^{2}$ et $\beta D$.

\section{DISCUSSION}

Les techniques d'électrophorèse, utilisées pour détecter le polymorphisme génétique des protéines, sont assez peu discriminantes. On peut calculer en effet que, dans le cas général, le tiers seulement des mutations ponctuelles du locus de structure d'une protéine se traduisent par une altération de la charge globale de cette protéine, proportion valable, en particulier, pour les caséines bovines (GRosCLAUDE et al., I972 a) ; de plus, une même altération de la charge globale peut être obtenue par mutation de plusieurs, voire de nombreux sites du locus de structure. L'emploi des termes de "variants génétiques " consacré par l'usage pour désigner les variants électrophorétiques d'une protéine, est donc très ambigu, puisqu'un variant électrophorétique peut représenter tout un ensemble de variants génétiques, ou mutants, de cette protéine.

De ces considérations découlent, pour l'analyse biochimique du polymorphisme électrophorétique d'une protéine, certaines conséquences pratiques :

- On peut attendre, en premier lieu, que l'étude biochimique des variants électrophorétiques d'une protéine conduise parfois à déceler d'autres altérations de structure primaire que celles qui sont responsables des différences de mobilité électrophorétique qui font distinguer ces variants. Cependant, la mise en évidence d'altérations n'ayant pas d'effet sur la charge globale est, dans ces conditions, tout à fait aléatoire; tant qu'on ne dispose pas de techniques permettant d'en faire un inventaire systématique dans les populations, il n'est donc pas judicieux de les placer sur le même plan que les altérations dont l'étude systématique peut être faite par électrophorèse. Dans cet ordre d'idées, le fait que les caséinomacropeptides des variants de type $x \mathrm{~A}$ dont nous avons étudié la structure primaire chez les bovins et les zébus diffèrent par une substitution I35 Thr $(x \mathrm{~A}$ bovin $) \rightarrow 11$ e $(x \mathrm{~A}$ zébu) représente sans doute un résultat intéressant : cependant, faute d'une étude systématique, rien ne permet d'affirmer que les deux variants ainsi mis en évidence sont effectivement confinés l'un chez Bos taurus, l'autre chez Bos indicus.

- On ne peut affirmer, en second lieu, tant que l'étude biochimique n'en a pas été menée à terme, que la différence de mobilité entre deux variants électrophorétiques dérive, dans toutes les populations où l'on trouve ces derniers, voire même au sein d'une population, d'un seul événement mutationel. C'est ainsi que la plupart des conclusions des études comparatives publiées jusqu'ici sur le 
polymorphisme des protéines de lait de bovins et de zébus étaient sujettes à caution puisque l'identité des variants électrophorétiques communs aux deux sous-genres n'avait pas été démontrée.

Le fait, mis en évidence par ce travail, que tous les variants électrophorétiques communs à Bos taurus et à Bos indicus $\left(\alpha_{s_{1}}-\mathrm{B}\right.$ et $\mathrm{C} ; \beta \mathrm{A}^{1}, \mathrm{~A}^{2}$ et $\mathrm{B} ; \varkappa \mathrm{A}$ et $\left.\mathrm{B}\right)$ diffèrent, dans les deux cas, par les mêmes substitutions d'acides aminés, constitue donc un résultat fondamental qui révèle de manière très concrète la parenté des bovins et des zébus; dans le cas particulier du variant $\beta B$ notre travail conduit donc à renoncer à désigner le variant de zébu par une notation particulière $(\beta \mathrm{Bz})$, puisque nous n'avons pas à tenir compte, nous l'avons vu plus haut, des altérations sans effet sur la charge, dont 1'existence est suggérée par la seule analyse biochimique d'un petit nombre d'échantillons (AschafFendurg et al., I968; Thompson et al., I969).

L'existence de variants communs à Bos taurus et à Bos indicus pose un problème d'histoire des bovinés. Selon EPSTEIN (I97I), le foyer d'origine des zébus se trouve en Asie du sud-ouest, en bordure est du grand désert salé d'Iran ; deux types différents de zébus auraient été successivement sélectionnés dans cette région à partir de bovins à longues cornes : un type à bosse cervico-thoracique, vers le quatrième millénaire avant notre ère, et un type à bosse thoracique vers le troisième millénaire. Or la domestication des bovins qui sont à l'origine des races Africaines actuelles, et qui seraient aussi, au moins en partie, à l'origine des races européennes, aurait également eu lieu en Asie du sud-ouest (Mésopotamie, Elam) vers les cinquième et troisième millénaires avant notre ère. On peut donc supposer que le polymorphisme commun aux bovins et aux zébus de notre époque existait déjà plusieurs millénaires avant notre ère dans les populations bovines d'Asie du sud-ouest. Pour expliquer le contraste entre la prédominance, au locus $\alpha_{s_{1}}$ Cn, de l'allèle $\alpha_{s_{1}}-\mathrm{Cn}^{\mathrm{B}}$ dans toutes les populations bovines et celle de l'allèle $\alpha_{s_{1}}-\mathrm{Cn}^{\mathrm{c}}$ dans toutes les populations de zébus, on peut remarquer que la domestication des bovins et des zébus a sans doute été effectuée, à 1'origine, en effectifs limités, ce qui a donné prise au jeu de la dérive génétique.

Les variants et les combinaisons alléliques de Bos taurus et de Bos indicus peuvent donc être regroupés en un arbre phylogénétique commun très cohérent (fig. 5) dans lequel il resterait cependant à désigner, entre $\alpha_{s_{1}}-\mathrm{Cn}^{\mathrm{B}}-\beta-\mathrm{Cn}^{\mathrm{A}^{2}}$ et $\alpha_{s_{1}}-\mathrm{Cn} \mathrm{C}-\beta-\mathrm{Cn}^{\mathrm{A}^{2}}$, la combinaison allélique originelle. La connaissance de la nature $\mathrm{du}$ résidu occupant, dans la chaîne de caséine $\alpha_{s_{1}}$ d'espèces voisines, la position homologue du résidu 192 de la caséine $\alpha_{s_{1}}$ de bovins ou de zébus pourra peut-être à l'avenir permettre d'avancer une hypothèse. Quoiqu'il en soit, la figure 5 permet d'illustrer une notion d'un intérêt tout à fait général et méritant réflexion dans le cadre de 1'analyse phylogénétique des populations animales : celle de 1'échelonnement dans le temps des événements mutationnels qui sont à l'origine des variants actuellement détectés. C'est ainsi que, si $\beta \mathrm{A}^{2}$ est bien le variant originel du locus $\beta-\mathrm{Cn}, \beta-\mathrm{A}^{1}$ est alors, selon toute vraisemblance, plus ancien que $\beta B$ et $\beta C$; on conçoit aussi qu'à côté des variants les plus anciens, communs aux bovins et aux zébus, d'autres variants soient apparus dans les deux sous-genres après leur divergence phylogénétique : ceci pourrait être le cas par exemple, au locus $\beta$-Cn, des variants $\beta D$ chez le zébu et $\beta A^{3}$ chez les bovins.

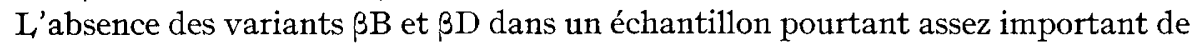




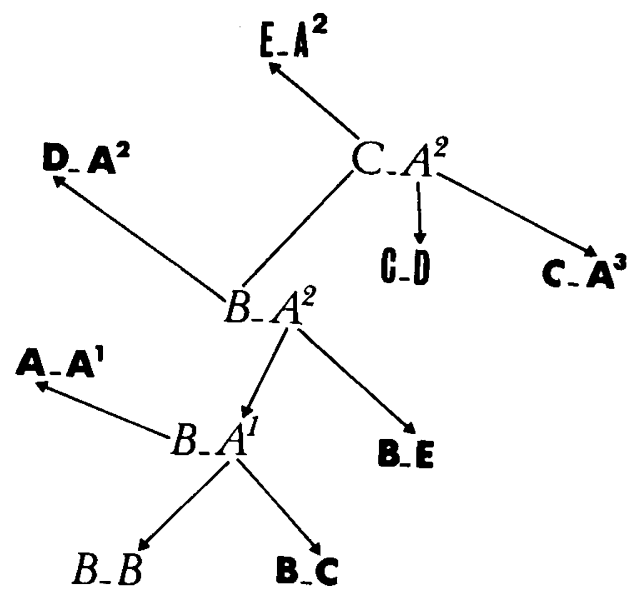

FIG. 5. - Phylogénie des combinaisons alléliques du couple $\alpha_{s_{1}}-C n-\beta-C n$ chez les bovins et les zébus, à l'exclusion des combinaisons recombinantes.

Pour $\mathrm{C}-\mathrm{A}^{2}$, lire $\alpha_{81}-\mathrm{Cn} \mathrm{C}-\beta-\mathrm{Cn}^{\mathrm{A}^{2}}$, etc. Les diverses combinaisons dérivent les unes des autres par mutation, soit au locus $\alpha_{s_{1}}$ - Cn soit au locus $\beta$-Cn (flèches). On ne peut encore désigner, entre $\alpha_{s_{1}}-\mathrm{Cn}^{\mathrm{B}}-\beta-\mathrm{Cn}^{\mathrm{A}^{2}}$ et $\alpha_{s_{1}}-\mathrm{Cn}_{n} \mathrm{C}-\beta-\mathrm{Cn}^{\mathrm{A}^{2}}$, la combinaison originelle. En italiques : combinaisons communes aux bovins et aux zébus; en caractères gras : combinaisons n'ayant été trouvées que chez des bovins; la combinaison $\alpha_{s_{1}} \mathrm{Cn}^{\mathrm{C}}-\beta-\mathrm{Cn}^{\mathrm{D}}$ n'a été trouvée que chez des zébus; sur ce schéma figure également la combinaison $\alpha_{s_{1}}-\mathrm{Cn}^{\mathrm{E}}-\beta-\mathrm{Cn}^{\mathrm{A}^{2}}$, découverte récemment chez des yaks (Bos poëphagus) au Népal (Grosclaude et al., I974a).

la population de zébus du nord-ouest et du sud de Madagascar est une observation intéressante que 1'on peut être tenté de rapprocher de la conception précédemment émise selon laquelle $\beta \mathrm{B}$ et $\beta \mathrm{D}$ sont des variants d'apparition plus récente que $\beta \mathrm{A}^{1}$. On sait malheureusement peu de choses de l'origine du zébu malgache. Selon VERIN (I967, I972) on trouve des ossements de zébus dans certains gisements subfossilifères les plus anciens de l'île. EPSTEIN (I97I) résume ainsi ses conclusions : "Avant le milieu du premier millénaire de notre ère, tous les immigrants à Madagascar étaient de race et de culture malaisiennes; ces immigrants semblent avoir introduit dans l'île le Zébu à bosse thoracique à partir de l'Inde ou du sud de l'Arabie. Vers le début du second millénaire, les premiers immigrants malaisiens ont été rejoints par des Indonésiens mêlés d'éléments Hamitiques ou Bantous de la côte azanienne (1), et par des Bantous de la côte est africaine. Avec ces immigrants, un type de bétail sans corne ainsi que du bétail Sanga... atteignirent Madagascar ". Ceci signifie que le peuplement en zébu de l'île s'est fait à partir de plusieurs apports successifs, dont certains très anciens, sans que l'on puisse préciser l'importance respective de ces divers apports. Il est clair en tous cas qu'une étude approfondie du polymorphisme des lactoprotéines dans les races d'Afrique et d'Asie du sud-ouest serait du plus haut intérêt, ainsi que des investigations dans d'autres régions de Madagascar que celles que nous avons visitées.

Le linkage étroit existant entre les loci $\alpha_{s_{1}}-\mathrm{Cn}, \beta$ - $\mathrm{Cn}$ et $x$-Cn se traduit, dans les races bovines - françaises par exemple — par un " déséquilibre de linkage " très 
accusé, toujours statistiquement significatif entre les allèles des loci $\alpha_{s_{1}}$ - $\mathrm{nn}$ et $\beta$-Cn, et en général significatif entre les allèles des loci $\alpha_{s_{1}}$-Cn et $x$-Cn d'une part, et $\beta$-Cn et $x$-Cn d'autre part (Grosclaude, I974). Entre les allèles des loci $\alpha_{s_{1}}$-Cn et $\beta$-Cn, le déséquilibre, particulièrement accusé, se traduit par l'absence ou l'extrême rareté des combinaisons alléliques recombinantes. C'est ainsi que la combinaison $x_{s_{1}}-\mathrm{Cn}^{\mathrm{C}}-\beta-\mathrm{Cn}^{\mathrm{A}^{1}}$ n'a pas encore été observée dans les ro races françaises étudiées jusqu'ici (environ 3 ooo analyses au total ; GROSCLAUDE, I974). Le présent travail indique que 1'on peut déceler, chez le Zébu malgache, un déséquilibre de linkage semblable à celui qui existe dans les populations bovines françaises; toutefois ce déséquilibre paraît moins accusé, et ceci se traduit en particulier, par l'existence chez le Zébu malgache, à côté des combinaisons $\alpha_{s_{1}}-\mathrm{Cn}^{\mathrm{B}}-\beta-\mathrm{Cn}^{\mathrm{A}^{2}}, \alpha_{s_{1}}-\mathrm{Cn}^{\mathrm{B}}-\beta-\mathrm{Cn}^{\mathrm{A}^{1}}$ et $\alpha_{s_{1}}-\mathrm{Cn}^{\mathrm{C}}-\beta-\mathrm{Cn}^{\mathrm{A}^{2}}$, de la combinaison $\alpha_{s_{1}}-\mathrm{Cn}^{\mathrm{C}}-\beta-\mathrm{Cn}^{\mathrm{A}^{1}}$; en démontrant que les substitutions d'acides aminés différenciant $\alpha_{s_{1}}-\mathrm{B} \mathrm{d}^{\prime} \alpha_{s_{1}}$-C et $\beta \mathrm{A}^{1} \operatorname{de} \beta \mathrm{A}^{2}$ étaient les mêmes quelle que soit la combinaison allélique considérée, nous avons démontré que cette combinaison $\alpha_{s_{1}}-\mathrm{Cn}^{\mathrm{c}}-\beta-\mathrm{Cn}^{\mathrm{A}^{1}}$ pouvait bien être considérée comme un recombinant.

De manière générale, on sait que la probabilité de fixation d'un recombinant dans une population, dépend de la valeur prise dans cette population par l'expression $\mathrm{N} e, \mathrm{~N}$ étant 1'“ effectif génétique ) de la population, et $e$ le taux d'apparition du recombinant (OHTA et KIMURA, I97I) ; ce dernier est le produit du taux de recombinaison intrinsèque entre les deux sites ségrégeant et de la probabilité du double hétérozygote : or on peut vérifier que celle-ci est actuellement du même ordre de grandeur chez le Zébu malgache et dans des races bovines françaises bien étudiées telles que la Montbéliarde et la Normande (Grosclaude et al., I966; Grosclaude, 1974); d'autre part le taux de recombinaison intrinsèque est sans doute le même chez les bovins et les zébus. Le fait que la combinaison $\alpha_{s_{1}}-\mathrm{Cn}^{\mathrm{C}}-\beta-\mathrm{Cn}^{\mathrm{A}^{1}}$ soit fixée chez le zébu malgache, et pas chez les bovins français, peut donc être attribué à une différence d'effectif génétique entre les populations considérées : il est certain en tous cas que la valeur de $\mathrm{N}$ dans les races françaises est actuellement suffisamment faible pour que $\mathrm{N} e$ soit très inférieur à $\mathrm{I}$; par contre, ce que l'on sait sur les méthodes d'élevage du zébu malgache suggère que l'effectif génétique y est suffisamment élevé pour que $\mathrm{N} e$ soit supérieur à $\mathrm{I}$. Toutefois, la solution de ce problème n'est peut-être pas aussi simple, car la réduction de l'effectif génétique des populations bovines françaises semble être un phénomène relativement récent.

La coexistence des complexes alléliques $\alpha_{s_{1}}-\mathrm{Cn}^{\mathrm{B}}-\beta-\mathrm{Cn}^{\mathrm{A}^{1}}$ et $\alpha_{s_{1}}-\mathrm{Cn}^{\mathrm{C}}-\beta-\mathrm{Cn}^{\mathrm{A}}{ }^{1}$ peut être rapprochée de celle des complexes $\alpha_{s_{1}}-\mathrm{Cn}^{\mathrm{B}}-\beta-\mathrm{Cn}^{\mathrm{B}}$ et $\alpha_{s_{1}}-\mathrm{Cn}^{\mathrm{C}}-\beta-\mathrm{Cn}^{\mathrm{B}}$, qui apparaît chez les zébus indiens et africains étudiés par AschafFEnBurg et al. (I968) encore qu'il serait utile, ici aussi, de vérifier que $\beta$ - $\mathrm{Cn}^{\mathrm{B}}$ commande le même mutant dans ces deux combinaisons. Par contre, 1'allèle $\beta$ - $\operatorname{Cn}^{D}$ a toujours été trouvé associé, jusqu'à présent, à $\alpha_{s_{1}}-\mathrm{Cn}^{\mathrm{C}}$ (AschafFEnBuRG et al., I968; GrosCLAUDE et al., I974). On notera que, selon la disposition relative des loci $\alpha_{s_{1}}$-Cn et $\beta$-Cn que nous avons proposée, (GROSCLAUDE et al., I972 c), les sites mutés différenciant $\alpha_{s_{1}} \mathrm{C} \mathrm{d}^{\prime} \alpha_{s_{1}} \mathrm{~B}$ et $\beta \mathrm{D}$ de $\beta \mathrm{A}^{2}$ peuvent être très proches sur le chromosome. Cependant, les fréquences alléliques sont telles (autour de 0,OI-0,03 pour la combinaison $\left.\alpha_{s_{1}}-\mathrm{Cn}^{\mathrm{c}}-\beta-\mathrm{Cn}^{\mathrm{D}}\right)$ que la probabilité des hétérozygotes susceptibles de produire des recombinants est nettement plus faible que dans le cas de la combinaison $\alpha_{s_{1}}-\mathrm{Cn}^{\mathrm{C}}-\beta-\mathrm{Cn}^{\mathrm{A}^{1}}$ par exemple (0,007 contre 0,04 environ); d'autres études de populations seraient donc souhaitables à ce stade. 
Notons enfin que l'analyse de la répartition des génotypes aux loci $\alpha$-La et $\beta-L g$ ne permet pas de déceler de linkage entre ces deux loci, contrairement à ce que pouvaient suggérer les données de BLumberg et Tombs (I958). La recherche de liaisons éventuelles entre $\alpha$-La et d'autres loci reste à faire.

Reçu pour publication en juillet 1974.

\section{REMERCIEMENTS}

Ce travail n'a pu être entrepris, en I968, que grâce à de nombreux concours : nous sommes en particulier redevables à M. J. J. Nataï, alors Ministre de l'A griculture, de l'Expansion Rurale et du Ravitaillement du Gouvernement Malgache, d'avoir bien voulu nous donner l'autorisation d'effectuer notre tournée de prélèvements d'échantillons de lait; M. J. PAGot, alors directeur général de l'I. E. M. V. T., M. J. Bustarret, alors directeur général de l'I. N. R. A., et M. J. PoLy, alors directeur du Département de Génétique animale de l'I. N.R. A. nous ont apporté un soutien important. Nous sommes reconnaissants à M. H. SerRes, alors inspecteur-en-chef au Laboratoive central de l'Élevage à Tananarive, à toute son équipe, ainsi qu'aux autorités locales, aux Services vétérinaires et aux éleveurs Malgaches d'avoir, par leur accueil, beaucoup facilité notre tâche sur le terrain.

L'analyse au spectromètre de masse a été effectuée par M. B. C. DAs, dans le service du Pr E. Lederer, à l'Institut de Chimie des substances naturelles, C. N. R. S., Gif-sur-Yvette. Nous remercions M. DAs de son aide. Nous remercions également les Dr A. Robertson et R. TomasSONE de leurs conseils.

\section{SUMMARY}

\section{A STUDY ON THE GENETIC POLYMORPHISM OF BOS INDICUS LACTOPROTEINS,}

\section{AS COMPARED WITH THAT OF BOS TAURUS}

778 whey and 586 casein solutions, prepared from individual milks of Malagasy zebus (Bos indicus), were examined by starch gel and polyacrylamide gel electrophoresis to determine the genetic polymorphism of the milk proteins, and to compare this polymorphism with that found in the milk proteins of the bovine (Bos taurus).

The structural loci of the main five lactoproteins ( $\alpha$-lactalbumin, $\beta$-lactoglobulin, $\alpha_{\delta 1^{-}}$, $\beta$-, and $x$-caseins) were all found to be biallelic and to determine the following classical variants ; La $\mathrm{A}$ and $\mathrm{B} ; \mathrm{Lg} \mathrm{A}$ and $\mathrm{B} ; \alpha_{s_{1}} \mathrm{~B}$ and $\mathrm{C} ; \beta \mathrm{A}^{\mathbf{1}}$ and $\mathrm{A}^{2} ; \varkappa \mathrm{A}$ and $\mathrm{B}$. Variants $\beta \mathrm{B}$ and $\beta \mathrm{D}$ were not found in the Malagasy zebu milks. Allelic frequencies observed in the sample, as well as frequencies of the allelic combinations controlled by the genetic unit formed by the three casein loci, $\alpha_{s_{1}}-\mathrm{Cn}, \beta-\mathrm{Cn}_{\mathrm{n}}$ and $x-\mathrm{Cn}$, are given in table $\mathrm{I}$. Comparison of the allelic frequencies observed in the five main geographical sub-samples indicates a certain genetic homogeneity in the zebu population studied.

The amino-acid substitutions responsible for the differences in electrophoretic mobility shown by variants $\alpha_{s_{1}} \mathrm{~B}$ and $\mathrm{C}, \beta \mathrm{A}^{1}$ and $\mathrm{A}^{2}$, and $\chi \mathrm{A}$ and $\mathrm{B}$, where characterized by essentially the same methods as those previously used by the authors for studying the variants of bovine caseins. All substitutions were identical to those found in bovine casein, including the case when variants $\alpha_{s_{1}}-\mathrm{C}$ and $\beta \mathrm{A}^{1}$ are controlled by the allelic combination $\alpha_{s_{1}}-\mathrm{Cn}^{\mathrm{C}}-\beta-\mathrm{Cn}^{1}$. [substitutions I92 Glu $\left(\alpha_{s_{1}}-\mathrm{B}\right) \rightarrow$ Gly $\left(\alpha_{s_{1}}-\mathrm{C}\right) ; 67$ Pro $\left(\beta \mathrm{A}^{2}\right) \rightarrow$ His $\left(\beta \mathrm{A}^{1}\right)$ and 148 Asp $(x \mathrm{~A}) \rightarrow$ Ala $\left.(\chi \mathrm{B})\right]$. In addition, the study of a sample of $\beta B$ casein, prepared from the milk of a Choa zebu (from the Republic of Chad) indicated that zebu $\beta B$ differed from $\beta A^{1}$ by the same substitution I22 Ser $\left(\beta \mathrm{A}^{1}\right) \rightarrow \operatorname{Arg}(\beta B)$ as in the bovine, a result which calls into question the use of the specific notation $\beta B z$ to designate zebu $\beta B$. It is most likely that for each of the three loci, the polymorphism common to Bos taurus and Bos indicus can be attributed to single mutations, that occured before the phylogenetic divergence of these two branches of the genus Bos, which, according to EPSTEIN (I97r), took place in south-west Asia, in the fourth and third millennium B. C. The fact that the predominant allele of locus $\alpha_{\delta_{1}}$-Cn is not the same in Bos taurus $\left(\alpha_{s_{1}}-\mathrm{B}\right)$ as in Bos indicus $\left(\alpha_{s_{1}}-\mathrm{C}\right)$ 
can be due to the effect of genetic drift during the phase of selection in small populations which probably accompanied domestication.

In addition to the two substitutions already found in the bovine $\left[\mathrm{I}_{4} 8 \mathrm{Asp}(x \mathrm{~A}) \rightarrow \mathrm{Ala}(x \mathrm{~B})\right.$ responsible for the difference in net charge, and I36 Thr $(\kappa \mathrm{A}) \rightarrow$ lle $(\kappa \mathrm{B})$, having no effect on net charge] the "caseino-macropeptides" of $\chi \mathrm{A}$ and $\chi \mathrm{B}$ variants in Malagasy zebus differed by a third substitution, 135 lle $(x \mathrm{~A}) \rightarrow$ Thr $(\varkappa \mathrm{B})$ which has no effect on the charge. However, since only a small number of casein samples was studied in both cases, no general conclusion can be drawn from this observation.

A sample of casein $\beta D$ was prepared from individual milks from two Nepalese yak $\times$ zebu cows : $\beta D$ differed from $\beta A^{2}$ by the substitution I $8 \operatorname{SerP}\left(\beta A^{2}\right) \rightarrow \operatorname{Lys}(\beta D)$. This substitution is probably the only one implicated in the difference in net charge between the two variants.

In contrast to the data, albeit limited, of BLUMBERG and ToMBS (1958), the repartition of genotypes at loci $\alpha$-La and $\beta-\mathrm{Lg}$ in our population sample of Malagasy zebu fits exactly with that expected from the hypothesis of genetic independence of the two loci. Regarding loci $\alpha_{s_{1}}$ - Cn and $\beta-C n$, the linkage disequilibrium in the zebu population studied — where the allelic combina-

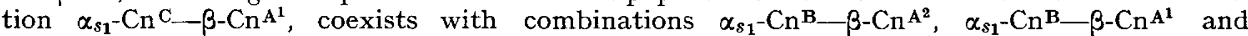
$\alpha_{\delta_{1}}-\mathrm{Cn} \mathrm{C}_{-}-\beta-\mathrm{Cn}^{2}$ - was not as strong as that which is observed in many western, especially French, breeds. This particular situation may be explained by the fact that the " effective size" of the Malagasy zebu population is probably much higher than that of most of the western breeds.

\section{RÉFÉRENCES BIBLIOGRAPHIQUES}

Aschaffenburg R., I968. Genetic variants of milk proteins; their breed distribution. J. Dairy Res., 35, 447-46o.

Aschaffenburg R., Drewry J., I959. New procedure for the routine determination of the various non casein proteins in milk. XVe Cong. Intern. Lait, 3, Sect. 5, I63I-I637.

Aschaffenburg R., Sen A., Thompson M. P., I968. Genetic variants of casein in Indian and African Zebu cattle. Comp. Biochem. Physiol. 25, I77-r 84 .

Bell K., Hopper K. E., McKenzie H. A., Murphy W. H., Shaw D. C., I97o. A comparison of bovine $\alpha$-lactalbumin A and B of Droughmaster. Biochim. biophys. Acta, 214, 437-447.

Bell K., McKenzie H. A., Shaw D. C., r968. Amino acid composition and peptide maps of B-lactoglobulin variants. Biochim. biophys. Acta, 154, 284-294.

Bhattacharya S. D., Roychoudhury A. K., Sinha N. K., SeN A., I963. Inherited $\alpha$-lactalbumin and $\beta$-lactoglobulin polymorphism in Indian Zebu cattle. Comparison of Zebu and Buffalo $\alpha$-Lactalbumins. Nature, 197, 797-799.

Blumberg B. S., Tombs M. P., 1958. Possible polymorphism of bovine $\alpha$-lactalbumin. Nature, 181, $683-684$.

Bracnitzer G., Chen R., Schrank B., Stangl A., I972. Automatische Sequenzanalyse eines Proteins. ( $\beta$-Lactoglobulin A B). Hoppe-Seyler's Z. Physiol. Chem., 353, 832-834.

Brew K., Castellino F. J., Vanaham T. C., Hill R. L., I97o. The complete amino acid sequence of bovine $\alpha$-lactalbumin. J. Biol. Chem., 245, 4570-4582.

Brignon G., Ribadeau-Dumas B., I973. Localisation dans la chaine peptidique de la $\beta$-lactoglobuline bovine de la substitution Glu/Gln différenciant les variants génétiques B et D. FEBS Lett., 33, 73-76.

Brignon G., Ribadeau-Dumas B., Grosclaude F., Mercier J.-C., i97i. Structure primaire de la caséine $\beta$ bovine. Eur. J. Biochem., 22, 179-185.

Ceppellini R., Siniscalco M., Smith C. A. B., I956. The estimation of gene frequencies in a randommating population. Ann. hum. Genet, 20, 97-Ir5.

Epstein H., I97I. The origin of the domestic animals of Africa. Africana publishing Corporation, New York, London, Munich. Vol. I, 573 p.

Grosclaude F., ig68. (Résultats non publiés).

Grosclaude F., I974. (Résultats non publiés).

Grosclaude F., Mahe M.-F., I97I. (Résultats non publiés).

Grosclaude F., Mahe M.-F., Mercier J.-C., Bonnemaire J., Teissier J.-H., i974a. Comparaison des variants électrophorétiques des protéines du lait de yaks (Bos poëphagus) avec ceux des bovins (Bos taurus) et des zébus (Bos indicus) (en préparation).

Grosclaude F., Mahe M.-F., Mercier J.-C., Ribadeau-Dumas B., I972 a. Caractérisation des variants génétiques des caséines $\alpha_{s_{1}}$ et $\beta$ bovines. Eur. J. Biochem., 26, 328-337.

Grosclaude F., Mahe M.-F., Mercier J.-C., Ribadeau-Dumas B., $1972 b$. Localisation des substitutions d'acides aminés différenciant les variants $\mathrm{A}$ et $\mathrm{B}$ de la caséine $\varkappa$ bovine. Ann. Génét. Sél. anim., 4, 5 I $5-52 \mathrm{I}$. 
Grósclaude F., Mahe M.-F., Voglino G.-F., I974 $b$. Le variant $\beta E$ et le code de phosphorylation des caséines bovines. FEBS Lett., 45, 3-5.

Grosclaude F., Mercier J.-C., Ribadeau-Dumas B., i97oa. Structure primaire de la caséine $\alpha_{s 1}$ bovine. Localisation des peptides trypsiques dans les fragments obtenus par hydrolyse trypsique de la caséine maléylée. Eur. J. Biochem., 14, 98-107.

Grosclaude F., Mercier J.-C., Ribadeau-Dumas B., ig7o $b$. Structure primaire de la caséine $\alpha_{s_{1}}$ bovine. Séquence des acides aminés de la partie $\mathrm{NH}_{2}$-terminale. Eur. J. Biochem., 16, 447-452.

Grosclaude F., Mercier J.-C., Ribadeau-Dumas B., 1972 c. Genetic aspects of cattle casein research. Neth. Milk Dairy J., 27, 328-340.

Grosclaude F., Pujolle J., Ribadeau-Dumas B., Garnier J., ig66. Analyse génétique du groupe de loci de structure synthétisant les caséines bovines; in : Polymorphismes biochimiques des animaux, 4I5-420. I. N. R. A., Paris.

Grosclaude F., Queval R., 1973. (Résultats non publiés).

Hrl W. G., 1974. Estimation of linkage disequilibrium in random mating populations. Heredity. (Sous presse).

Huang W. Y., TANG J., I970. Carboxyl-terminal sequence of human Gastricsin and Pepsin. $J$. Biol. Chem. 245, $2189-2193$.

Mercier J.-C., Brignon G., Ribadeau-Dumas B., 1973. Structure primaire de la caséine $\chi B$ bovine. Séquence complète. Eur. J. Biochem., 35, 222-235.

Mercier J.-C., Grosclaude F., Ribadeau-Dumas B., ig7o $a$. Structure primaire de la caséine $\alpha_{81}$ bovine. Séquence des 48 résidus de l'extrémité COOH-terminale. Eur. J. Biochem., 14, 108-119.

Mercier J.-C., Grosclaude F., Ribadeau-Dumas B., r97o $b$. Structure primaire de la caséine $\alpha_{s_{1}}$ bovine. Enchaînement des peptides obtenus par action du bromure de cyanogène et des peptides résultant de l'hydrolyse trypsique de la caséine $\alpha_{s_{1}}$ maléylée. Eur. J. Biochem., 16, 439-446.

Mercier J.-C., Grosclaude F., Ribadeau-Dumas B., i97I. Structure primaire de la caséine $\alpha_{s_{1}}$ bovine; Séquence complète. Eur. J. Biochem., 23, 4I-5I.

Mercier J.-C., Maubois J.-L., Poznanski S., Ribadeau-Dumas B., I968. Fractionnement préparatif des caséines de vache et de brebis par chromatographie sur DEAE-cellulose, en milieu urée et 2mercapto-éthanol. Bull. Soc. Chim. Biol., 50, 521-530.

Oнта T., Kimura M., I97I. Linkage disequilibrium between two segregating nucleotide sites under the steady flux of mutations in a finite population. Genetics, 68, 571-580.

Peterson R. F., I963. High resolution of milk proteins obtained by gel electrophoresis. J. Dairy Sci., 45, II36-II39.

Peterson R. F., Kopfler F. C., I966. Detection of new types of $\beta$-casein by polyacrylamide gel electrophoresis at acid pH : a proposed nomenclature. Biochem. biophys. Res. Commun., 22, 388-392.

Ribadeau-Dumas B., Brignon G., Grosclaude F., ig7 I a. Structure primaire de la caséine $\beta$ bovine. Enchaînement des 32 résidus d'acides aminés de la partie $\mathrm{NH}_{2}$-Terminale. Eur. J. Biochem., 20, 264268.

Ribadeau-Dumas B., Brignon G., Grosclaude F., Mercier J.-C., I972. Structure primaire de la caséine $\beta$ bovine. Séquence complète. Eur. J. Biochem. 25, 504-5 I4.

Ribadeau-Dumas B., Grosclaude F., Mercier J.-C., 1970. Structure primaire de la caséine $\beta$ bovine. Isolement et composition en amino-acides des peptides trypsiques et des peptides obtenus par action du bromure de cyanogene. Eur. J. Biochem., 14, 45I-459.

Ribadeau-Dumas B., Grosclaude F., Mercier J.-C., I971 $b$. Structure primaire de la caséine $\beta$ bovine. Enchaînement des peptides trypsiques et des peptides obtenus par action du bromure de cyanogène. Eur. J. Biochem. 18, 252-257.

Thомas D. W. Mass spectrometry of $\mathrm{N}$-permethylated peptide derivatives; artifacts produced by C-methylation. FEBS Lett., 5, 53-56.

Thompson M. P., Gordon W. G., Pepper L., Greenberg R., 1969. Amino acid composition of $\beta$-caseins from the milks of Bos taurus and Bos indicus cows : a comparative study. Comp. Biochem. Physiol., 30, 91-98.

Verin P., I967. Le Bœuf dans l'histoire ancienne de Madagascar. Revue de Madagascar, 38, 35-3.7.

VERIN P., I972. (Communication personnelle).

Vilkas E., Lederer E., Massot J.-C., r968. N-méthylation de peptides par la méthode d'Hakomori. Structure du mycoside $\mathrm{C}_{\mathrm{b}_{1}}$. Tetrahedron Lett., 26, 3089-3092.

Wake R. G., Baldwin R. L., I96r. Analysis of casein fractions by zone electrophoresis, in concentrated urea. Biochim. biophys. Acta, 47, 225-239. 